\title{
Using C. elegans to Decipher the Cellular and Molecular Mechanisms Underlying Neurodevelopmental Disorders
}

\author{
Carlos Bessa • Patrícia Maciel • \\ Ana João Rodrigues
}

Received: 30 December 2012 / Accepted: 26 February 2013

(C) Springer Science+Business Media New York 2013

\begin{abstract}
Neurodevelopmental disorders such as epilepsy, intellectual disability (ID), and autism spectrum disorders (ASDs) occur in over $2 \%$ of the population, as the result of genetic mutations, environmental factors, or combination of both. In the last years, use of large-scale genomic techniques allowed important advances in the identification of genes/loci associated with these disorders. Nevertheless, following association of novel genes with a given disease, interpretation of findings is often difficult due to lack of information on gene function and effect of a given mutation in the corresponding protein. This brings the need to validate genetic associations from a functional perspective in model systems in a relatively fast but effective manner. In this context, the small nematode, Caenorhabditis elegans, presents a good compromise between the simplicity of cell models and the complexity of rodent nervous systems. In this article, we review the features that make C. elegans a good model for the study of neurodevelopmental diseases. We discuss its nervous system architecture and function as well as the molecular basis of behaviors that seem important in the context of different neurodevelopmental disorders. We review methodologies used to assess memory, learning, and social behavior as well as susceptibility to seizures in this organism. We will also discuss technological progresses applied in C. elegans neurobiology research, such as use of microfluidics and optogenetic tools. Finally, we will present some interesting examples of the functional analysis of
\end{abstract}

C. Bessa $\cdot$ P. Maciel $\cdot$ A. J. Rodrigues

Life and Health Sciences Research Institute (ICVS),

School of Health Sciences, University of Minho, Braga, Portugal

C. Bessa $\cdot$ P. Maciel $\cdot$ A. J. Rodrigues $(\bowtie)$

ICVS/3B's-PT Government Associate Laboratory,

Braga/Guimarães, Portugal

e-mail: ajrodrigues@ecsaude.uminho.pt genes associated with human neurodevelopmental disorders and how we can move from genes to therapies using this simple model organism.

Keywords Neurodevelopment $\cdot$ C. elegans $\cdot$ Autism . Epilepsy $\cdot$ Intellectual disability

Neurodevelopmental Disorders: Past, Present, and Future

Development of a fully functional nervous system comprises many cellular and molecular events, which need to occur in a precise and ordered manner. These include cell proliferation; migration; programmed cell death; cell differentiation (involving morphological and biochemical specializations); establishment of contacts between neurons, synapses, and pruning of less efficient ones; and also establishment of specialized relationships between neurons and other cell types. Disturbances in any of these steps will lead to loss of viability, if severe, or to neurodevelopmental disorders, if more subtle. Neurodevelopmental disorders as a group occur in over $2 \%$ of the population and comprise intellectual disability (ID), epilepsy, autism spectrum disorders (ASDs), specific reading or writing impairments, hyperactivity, and attention deficit disorder, among others. Schizophrenia is also often seen as a neurodevelopmental disturbance manifesting only in adulthood. These disorders have an important impact in society, affecting not only the patients but whole families, especially when the care network is not well structured. They may result from genetic factors or from environmental interference with normal development process, as occurs, for instance, in the case of fetal alcoholic syndrome. Some of the effects of the environment may even be potentiated by a susceptible genetic background. 
Recently, important advances in our knowledge of genetic causes of neurodevelopmental diseases have emerged as a result of application of novel genomic analysis technologies (reviewed in [1]). To illustrate this, the genetic basis of disease can now be identified in up to $80 \%$ of patients with ID, when applying array comparative genomic hybridization and whole exome sequencing techniques. Additionally, many gene variants putatively associated with more complex, multifactorial neurodevelopmental disturbances have also been identified in the last years using genetic linkage and association analyses. Nevertheless, following identification of novel gene variants potentially causing the disease of interest, difficulty is often the interpretation of findings, namely, lack of information on gene function and on the effect of a given mutation in the corresponding protein. This brings the need for model systems that can be used to study genes and mutations of interest in a relatively fast but effective manner.

\section{Studies of Human Neurodevelopmental Genes in Lower Organisms}

Geneticists have harnessed the power of model organisms for understanding of human gene function for many years now, with flies, yeast, and mouse leading the way. In a simpler perspective, human neuronal cell lines can be a very interesting model to study the function of genes identified as associated with human neurodevelopmental diseases, given presence of majority of molecular components. However, given their lack of integration in functional circuits; lack of interaction with other cell types, also relevant for function of the nervous system; and absence of a behavioral output that allows assessment of effectiveness of the circuits, for many studies, there is the need to use a whole organism approach. Mice have been used for this purpose with very encouraging results: globally, the structure of the human and murine nervous systems bears significant resemblance and even at the behavioral level, paradigms have been developed to analyze traits that are thought to be parallel between these two species. Rat models are even more advantageous (particularly in cognitive and social studies), but the tools for genetic manipulation have lagged behind. Disadvantages of the use of rodents are their relatively high maintenance costs and difficulty/cost/time consumption of their genetic manipulation. On the other hand, the complex structure of their nervous system, which is certainly advantageous for some studies, also presents serious constraints when trying to dissect molecular events leading to disease. In this perspective, organisms with simpler nervous systems and genetic amenability provide an elegant framework for the study of gene function and malfunction.

A simpler species in which neurobiology of memory has been widely studied, but in which genetic manipulation has not been so developed, is Aplysia californica. Aplysia has a relatively small number of neurons, and many of them are enormous, allowing electrophysiological studies, individual neuronal manipulation, and observation of their neuronal architecture. Moreover, its neurons are able to form and store memories, have plasticity, and for several of them, a functional role has been determined [2]. In contrast, Drosophila melanogaster is a model in which genetic tools are highly developed and which has been increasingly used in behavioral genetic studies, the advantage being that it has a brainlike structure and complex behaviors that can be analyzed. Moreover, identification of specific neuronal populations and neuron-to-behavior output has advanced greatly in recent years [3]. Zebrafish is also a simple model that has the main advantage of being a vertebrate with a high degree of genetic homology with mammals. Because it has a brain, zebrafish is often envisaged as the bridge between Drosophila/worms and murine models. This animal model has been widely used to study human neurological disorders because of its low maintenance cost, rapid life cycle, rapid external embryonic development, and optical clarity of embryos and larvae, which allows observation of the nervous system in vivo. In addition, both gain- (overexpression of mutated proteins) and loss-of-function (morpholinos; zinc finger nuclease deletions, etc.....) approaches can be considered to study gene function [4]. Finally, for very simple functional genomic studies, yeast and other fungi can also be used, with the advantage of simplicity and ease of genetic manipulation but with clear limitations when it comes to understanding function of a gene within the nervous system.

\section{Caenorhabditis elegans as a Simple Model to Study Complex Neuronal Phenomena}

C. elegans provides a good compromise between complexity of vertebrates like mouse and extreme simplicity of yeast and is a reference model in studying function and malfunction of the nervous system. This animal presents key advantages that make it unique in the field of neurosciences: first, the well-described neuronal lineage and interconnectivity provides an exceptional set up for the study of neuronal mechanisms. Second, amenability to genetic manipulation allows identification of genes important for neuronal formation, migration, and activity. Third, its transparency in combination with existence of specific transgenic reporter strains allows in vivo monitoring of particular neuronal events, with possibility of correlating temporal patterns of neuronal activity with behavioral outcomes. Herein, we will describe the model, tools available in the field, and some of the remarkable contributions of this nematode for the understanding of nervous system function and dysfunction, and its underlying genetics, with particular 
Mol Neurobiol

172 focus on neurodevelopmental disorders such as epilepsy, 173 ASDs, and ID.

\section{C. elegans Nervous System}

While neuronal wiring diagrams in higher species such as rodents often present ambiguities and misinterpretations inherent to their complexity, simplicity of the $C$. elegans nervous system and its well-described anatomy and interconnectivity make this model an attractive and complementary tool in the field of neuroscience. The hermaphrodite C. elegans has 302 neurons divided in surprising 118 distinct neuronal classes and 56 glial cells, altogether comprising $37 \%$ of all the somatic cells in the worm $[5,6]$. Neuronal classes include 39 classes of predicted sensory neurons, 27 of motor neurons, and the remainder as interneurons [7]. Lineage and morphology have been described in detail [6], and there are fluorescent reporter genes for almost every neuron with exquisite specificity (some examples are in Table 1 and Fig. 1) [5, 8, 9].

Worm synapses (around 7,000) occur en passant, i.e., synaptic boutons are formed along the axon shaft $[10,11]$. The presynaptic site bears much resemblance to those of vertebrate nervous system, but the postsynaptic region appears to be simpler. The number of synapses between each partner can go up to 19 but normally is around five synapses $[10,11]$. It is also possible to observe synapses in vivo by using fluorescent reporter molecules such as synaptobrevin (SNB-1) [12], an integral membrane protein of synaptic vesicles. Importantly, this marker not only allows determination of synaptic density because synaptobrevin puncta correlates with the number of synaptic vesicles in ultrastructural studies but also is a measure of steady-state rates of vesicles exocytosis and endocytosis (intensity of synaptobrevin in axons) $[13,14]$. In an elegant RNA interference (RNAi) screening study that aimed to identify genes regulating GABA Caenorhabditis Genetics Center (CGC)
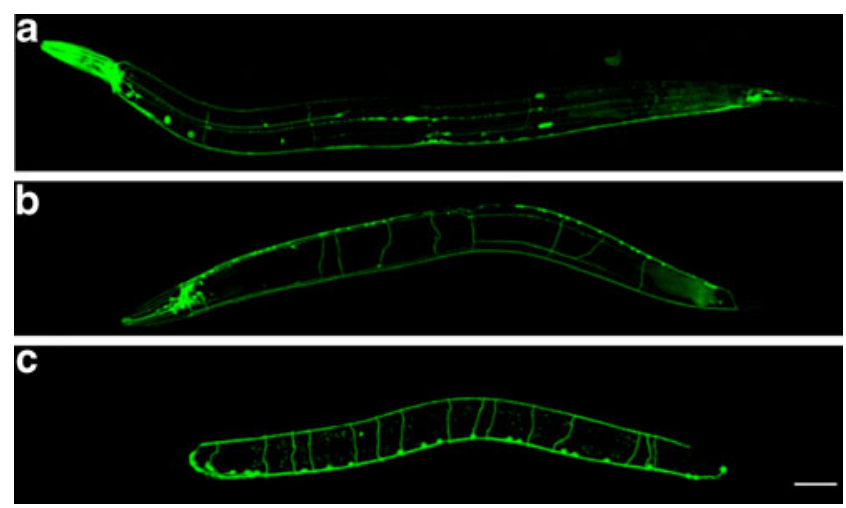

Fig. 1 Confocal pictures of commonly used C. elegans strains that express GFP in specific neurons. a Pan-neuronal expression of GFP observed in OH441 strain. This strain expresses GFP under the control of unc-119 promoter. The function of UNC-119 is still unknown, but this protein is necessary for neuronal formation and migration, is expressed since early embryonic stages until adulthood, and is present in nearly all neurons. b Strain LX929 expressing GFP in all cholinergic neurons. The fluorescent protein is in frame with UNC-17, a synaptic vesicle acethylcholine transporter. c Expression of GFP in all GABAergic neurons in strain EG1285. The fluorescent marker is expressed under the control of unc-47 promoter; UNC-47 is a transmembranar vesicular GABA transporter. Scale $50 \mu \mathrm{m}$

synapses, use of SNB-1::GFP marker allowed researchers to obtain insight on the nature of different neuronal defects [15]. By changing the promoter that controlled the marker, one could assess synaptic condition in either inhibitory (GABAergic) or excitatory (cholinergic) inputs of the neuromuscular junction (NMJ). Use of additional markers such as the postsynaptic UNC-49 GABAA receptor even allowed researchers to distinguish pre- from postsynaptic defects [15]. Moreover, specific markers of the active zone (specialized synaptic structures that mediate neurotransmitter release) were developed, such as SYD-2::GFP, which allows their direct visualization [16] and isolation of mutants with defective active zone morphology $[17,18]$.

Table 1 Some examples of C. elegans strains expressing a fluorescent marker in a specific group of neurons. All referred strains are available at the

\begin{tabular}{|c|c|c|c|}
\hline Strain & Genotype & Description & Expression pattern \\
\hline OH441 & otIs $45 \mathrm{~V}$ & Integrated Ex[unc-119::GFP] & Pan-neuronal marker \\
\hline NM440 & unc-104(e1265); jsIs1 & jsIs1[pSB120 (snb-1::GFP); pRF4 (rol-6(su1006))] & Nerve ring, ventral cord, dorsal cord \\
\hline SK4005 & $z d I_{s} 5$ & $z d I s 5[m e c-4:: G F P+\operatorname{lin}-15(+)(p S K 1)]$ & Touch neurons \\
\hline LX929 & vsIs 48 & $v s I s 48[u n c-17: \because G F P]$ & All cholinergic neurons \\
\hline EG1285 & lin-15B(n765); oxIs 12 & oxIs $12[u n c-47 p: \because G F P+\operatorname{lin}-15(+)]$ & All GABAergic neurons \\
\hline CZ333 & juIs1 & juIs $1[u n c-25 p: \because s n b-1: \because G F P+\operatorname{lin}-15(+)]$ & $\begin{array}{l}\text { Presynaptic terminals of GABAergic DD and } \\
\text { VD motor neurons and RME neurons }\end{array}$ \\
\hline NM306 & jsIs 1 & jsIs1[pSB120(snb-1::GFP) + pRF4(rol-4(su1006))] & Nerve ring, ventral cord and dorsal cord \\
\hline OH7547 & otIs 199 & $\begin{array}{l}\text { otIs } 199[\text { cat- } 2:: G F P+\text { rgef-1(F25B3.3):: dsRed }+ \\
\quad \text { rol-6(su1006)] }\end{array}$ & $\begin{array}{l}\text { Dopaminergic neurons and dsRed expressed } \\
\text { pan-neuronally }\end{array}$ \\
\hline BZ555 & egIs 1 & egIs $1[P$ dat $-1: \because G F P]$ & Dopaminergic neuronal soma and processes \\
\hline
\end{tabular}


C. elegans presents a stereotyped synaptic positioning, both the number and type of synaptic connections formed being similar between individuals ( $75 \%$ reproducibility) $[6$, $10,11,19]$. Yet, recent studies demonstrate that, as in mammals, synaptic activity may play a decisive role in shaping synaptic patterns after the initial pattern is established. As an example, mutants with reduced cholinergic synaptic transmission present enhanced sprouting of cholinergic SAB neurons [20].

Considering its simplicity, invariant neuronal network, and all the markers available, it is fairly easy to score (neuro)developmental defects in $C$. elegans, making this model a powerful tool to identify genes involved in neuronal formation and maturation and axonal outgrowth and migration. Despite its simplicity, C. elegans neurons use an array of classical neurotransmitters similar to those of mammals such as acetylcholine, dopamine, serotonin, GABA, and glutamate, whereas histamine, epinephrine, and norepinephrine seem to be absent [5].

Acetylcholine is the major excitatory neurotransmitter at nematode NMJs, and more than a third of the cells release acetylcholine, which is important for locomotion, egg laying, feeding, and male mating [21]. Aldicarb inhibits acetylcholinesterase, the enzyme responsible for hydrolysis of acetylcholine, culminating in buildup of this neurotransmitter, causing paralysis. Thus, several genes involved in biosynthesis and metabolism of acetylcholine have been identified by presence of the "Ric" phenotype (for resistance to inhibitors of cholinesterase) in response to aldicarb or other similar compounds [22].

As in mammals, fast excitatory neurotransmission in $C$. elegans is mainly glutamatergic, and both excitatory and inhibitory ionotropic glutamate receptors (iGluR) exist [23-25]. Glutamate-gated chloride channels are also present, though less studied and well understood [26]. iGluR are important for locomotion, feeding, defecation, and recently, were shown to be a determinant for learning and memory formation. For example, eat-4 encodes a vesicular glutamate transporter highly expressed in sensory neurons that respond to tapping [27-29], and deletion of this gene induces a more rapid habituation to tap [29, 30], suggesting a crucial role for glutamate in this type of learning. Interestingly, complementation with the human counterpart reverts the impairment, suggesting a common functional role [31]. Furthermore, in certain paradigms, worms can learn to associate paired stimuli and this is dependent on $g l r-1$ [32].

Bioamines, such as canonical dopamine and serotonin and the invertebrate-specific octopamine and tyramine, act in both neurons and muscles to affect egg laying, pharyngeal pumping, locomotion, and learning [33]. Such as in mammals, dopamine D1 and D2 receptors (dop-1 and dop-3, respectively) can act antagonistically, and their balance in specific dopaminergic neurons tightly controls response to food [33, 34]. Similar to vertebrates and in further support of common neurotransmitter systems, in C. elegans, exposure to 6-OHDA induces programmed cell death in dopaminergic neurons [35-37].

GABA is an important inhibitory neurotransmitter in $C$. elegans, but in contrast to vertebrates where it acts at synapses of the central nervous system, in nematodes, GABA acts primarily at neuromuscular synapses, being important for locomotion, defecation, and foraging [38]. GABA is expressed in 26 of the 302 neurons present in C. elegans, and the proteins involved in GABA biosynthesis and transport are remarkably conserved (Fig. 2). Such as in mammals, there are two types of receptors, $\mathrm{GABA}_{\mathrm{A}}$ and $\mathrm{GABA}_{\mathrm{B}}$, based on sequence similarity [39-42].

In addition to conventional neurotransmitter molecules, to date, 113 genes encoding over 250 distinct neuropeptides have been identified in worms [43]. These neuropeptides are involved in a wide range of worm behaviors such as locomotion, egg laying, social behavior, and ethanol response [43] and are expressed in both nervous and non-nervous tissues. Of these, 40 encode insulinlike peptides (ins family), 31 encode FMRFamide-related peptides (FLPs), and 42 encode other types of peptides (neuropeptidelike peptides, NLPs). Neuropeptides are short amino acid sequences that act directly (as primary neurotransmitters) or indirectly to modulate synaptic function. Identification of neuropeptides and their receptors is a complicated task since peptides may functionally overlap and are able to bind to various receptors, depending on the physiological condition of the animal. Among the most studied neuropeptides are members of the insulinlike family, such as ins- 1 , highly expressed in neuronal tissues and that have been shown to regulate reproductive growth and longevity [44]. Under harsh environmental conditions, C. elegans undergoes an alternative life stage, called dauer, and this decision is dependent on the activity of an insulinlike receptor, $d a f-2$, and $d a f-28$, a beta-type insulin [45]. Involvement of this signaling pathway in longevity, discovered in C. elegans, has also been identified in Drosophila and mammals [46-48].

While it is undeniable that neurotransmitter systems and neuropeptides are significantly conserved in C. elegans, we cannot overlook the fact that worm findings do not always mimic the human picture nor are easily translatable. As an example, fluoxetine, a serotonin reuptake inhibitor, is an antidepressant in humans and other mammals, while in worms, it is a potent stimulator of egg-laying [49-51]; these two apparently unlike phenotypes are the result of similar neuronal control by serotonin. In mammals, cocaine primarily exerts its behavioral effects by inhibiting dopamine reuptake, leading to a stimulant effect. In contrast, in worms, cocaine leads to hypolocomotion and its effects are not dependent on dopamine, being mediated by the ionotropic serotonin receptor MOD-1 [52]. These pitfalls cannot be 


\section{GABA Signaling}

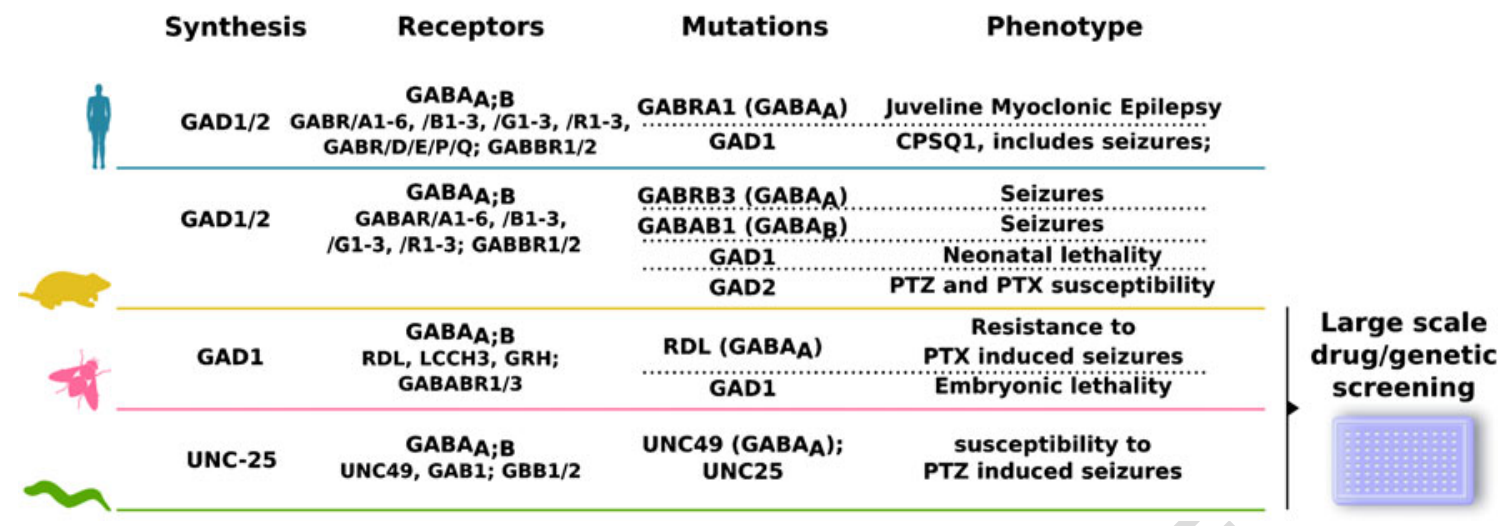

Fig. 2 Evolutionary conserved GABAergic signaling. The proteins involved in the metabolism of GABA and its receptors are remarkably conserved in humans, mice, Drosophila, and C. elegans. Mutations in GAD1 have been associated with recessive cerebral palsy, a condition in which patients often present seizures. Murine knockout models for Gad1 and Gad2 also display seizures. Wild type worms are resistant to proconvulsing effects of pentylenetetrazol (PTZ); however, knockout

neglected but this nematode is still an attractive and complementary model to study cellular and molecular mechanisms underlying neuronal phenomena. Furthermore, its tractability, genetic amenability, and feasibility of doing large-scale analysis have led to substantial use of this model in drug and/or genetic screenings. Among all the models, $C$. elegans is the most cost-effective to use in high-throughput analysis and still offers the advantage of being a multicellular organism in comparison with cell culture systems or yeast (reviewed in [53]).

\section{A Simple Organism Presenting Complex Behaviors}

In contrast to its simplicity, in terms of neuronal architecture, C. elegans presents a repertoire of relatively complex behaviors. Worms can sense hundreds of different odors even at a very low concentration, discriminate among them, and generate behavioral responses that are appropriate to the cue. Similarly, C. elegans is able to sense a variety of noxious stimuli, including low $\mathrm{pH}$, heavy metals, detergents, and high osmolarity [54-58], using specific sensory neurons identified by laser ablation studies (reviewed in [7]). Simplicity of the neuronal circuit allowed identification of neurons (and genes) involved in sensing and discrimination of several of these compounds. Interestingly, worms present some degree of olfactory adaptation given that naïve animals will respond more than preexposed animals to a variety of signals. Moreover, C. elegans is capable of learning the odors of different bacteria and avoid strains that make them ill [59]; these learned olfactory behaviors are associated with neurochemical changes that induce behavioral (re) animals for unc-25 (GAD1/2 ortholog) present PTZ-induced convulsions. Drosophila deletion of Gadl gene is lethal. Mutations in $\mathrm{GABA}_{\mathrm{A}}$ receptors have been associated with epilepsy in humans. In mice, deletion of both $\mathrm{GABA}_{\mathrm{A}}$ and $\mathrm{GABA}_{\mathrm{B}}$ increases seizure susceptibility. Worm mutants for $\mathrm{GABA}_{\mathrm{A}}$ receptor unc-49 also present severe PTZ-induced convulsions. On the contrary, Drosophila $R d l$ knockouts are resistant to picrotoxin (PTX)-induced seizures. [137, 143, 277, 293-298]

modeling. Curiously, C. elegans sensory perception is also able to regulate its longevity, suggesting that in nature, lifespan may be regulated by environmental cues rather than being determined solely genetically [60], a finding later confirmed in Drosophila [61].

Pioneering studies have proven that worms are able to learn and present both short- and long-term memory underlying the nonassociative form of learning-habituation [29, $30,62,63]$. Later, evidence showed that worms also present classical conditioning/associative learning using different types of stimuli (chemosensory and thermosensory) [32, $64,65]$. As an example, worms chemotax to $\mathrm{NaCl}$ if previously associated with food [66, 67]. Similarly, in a temperature gradient plate, worms will migrate to the foodassociated temperature with remarkable accuracy $[64,68]$. Conversely, animals can also make a negative association if the attractant was previously associated with an aversive stimulus such as starvation [69]. In mammals, learning is strongly dependent on experience-dependent synaptic changes in glutamatergic synapses. Likewise, glutamatergic transmission is important for behavioral plasticity and learning in $C$. elegans. For example, glr-1 (AMPA-type glutamate receptor) mutations block olfactory associative and nonassociative learning in C. elegans $[30,32,70]$. As mentioned before, eat-4, encoding a vesicular glutamate transporter, is crucial for tap habituation learning [30].

Similar to other species, distributed training (blocks of stimuli separated by longer resting periods) appears to be fundamental for long-term memory formation in $C$. elegans, in contrast with massed training (similar number of stimuli in just one block) [71]. C. elegans goes beyond simple learning and memory, presenting context 
conditioning that is sensitive to latent inhibition and extinction (reviewed in [7]).

C. elegans also presents some degree of social interaction, and this is controlled by the neuropeptide Y (NPY) receptor (NPR-1). Some strains, upon encountering food/bacteria, reduce locomotion and disperse in the bacteria lawn and feed individually, whereas other strains move fast across the lawn and aggregate [72]. A single nucleotide substitution in the receptor was shown to be sufficient to transform the isolated strains to become social. In mammals, NPY and its receptors are involved in regulation of food consumption, anxiety, and stress resilience (reviewed in [73]), a somewhat different role from that in nematodes. Yet, recent work suggests that social isolation can induce expression changes in NPY in mammals [74] and that administration of an antagonist of NPY receptor subtype 2 (Y2R) can revert nicotine-induced social anxiety [75], suggesting that NPY can also play a key role in social behavior in higher species.

\section{Cutting Edge Tools in the Field}

Due to its size and easy and unexpensive maintenance and tractability, C. elegans is suitable to large genetic and drug screenings. This is a noteworthy benefit of using this model in the initial study of several disorders, including those of the nervous system. Generation of knockout and transgenic strains is a relatively straightforward process and certainly less time- and money-consuming than in other species. Apart from classical mutagenesis (chemically induced or by radiation), we can also take advantage of RNAi, a technique that is well established in worms and works for most genes. However, systemic delivery of RNAi (usually by feeding worms with bacteria expressing the interest dsRNA) occasionally masks pertinent neuronal phenotypes and commonly neurons are refractory to classic RNAi [76]. Since RNAi is a powerful tool to ascertain gene function, several groups have tried to overcome difficulty of achieving efficient neuronal RNAi silencing in C. elegans either by using specific RNAi-sensitive strains [77] or simply based on the expression under neuronal specific promoters of sense and antisense RNAs corresponding to the gene of interest [78]. Others have developed a knockdown technique based on the in vivo expression of heritable inverted-repeat genes. This approach allows effective gene inactivation in the nervous system in a time-specific manner using inducible promoters, for example. Moreover, stable lines harboring the transgene can be easily maintained [79]. Besides deletion/knockdown of specific genes, increasing evidence suggests that several neurodevelopmental disorders present a dosage defect rather than a loss-of-function mutation. In this perspective, $C$. elegans is still a very attractive model, since it is fairly easy to create transgenic animals and control expression of genes with temporal and cellular specificity by use of specific promoters.

In the last years, several technical improvements have been implemented in the study of $C$. elegans nervous system, some of them simple to set up and some other requiring a significant optimization process. Live imaging is particularly attractive and simple to use in C. elegans considering its transparency and well-described anatomy. In addition to fluorescent markers that tag specific neuronal populations, one can monitor neuronal excitability in vivo and in freely moving animals by live calcium imaging [80]. For example, calcium imaging studies determined that the AWC neuron responds to temperature changes and that response thresholds differ depending on previously experienced temperature [81]. Using the same technique, others have shown that the AFD neuron transmits both stimulatory and inhibitory temperature signals and that the activity of this neuron is compromised in animals depleted for CREB, a protein necessary for memory and learning [82]. This technique allows multiple neuronal recording and temporal correlation of neuronal activity but it is always dependent on imaging methods and is often inadequate to detect subthreshold membrane potential changes [83]. Other precise but drastically more invasive methods have been adopted, such as electrophysiological measurements, though several constraints exist considering the highly pressurized $C$. elegans body and the small size of its neuronal cell bodies (reviewed in [84]). Nevertheless, with careful dissection and some training, it is possible to obtain reliable data using this technique. Patch clamping was initially performed in the pharynx, in which the contraction (as in other fast muscles) is controlled by changes in membrane electrical potential because it was easier to identify and access. By recording pharyngeal activity, several studies have identified mutations in presynaptic proteins [85] and ion channels [86]. Later studies were performed in exposed neurons from dissected animals [87] and some were even able to record touch response currents from PLM mechanosensory neurons [88]. Electrophysiological recording of both endogenous excitatory and inhibitory postsynaptic currents of the NMJ was an excellent tool to identify important genes in the control of GABA or acetylcholine release [89]. An adaptation of this technique was also applied to record currents from head neurons with success [90-92].

Besides genetic manipulation of selected neuronal subtypes, it is possible to perform specific neuronal laser ablation in C. elegans in order to better dissect the function of a particular neuron or group of cells. This technique was used with success to scrutinize the neural circuit underlying habituation [93, 94], thermotaxis [95, 96], and head-touchmediated backward movements [93, 97]. Manipulations of the timing of laser ablation during the training process of the 
Mol Neurobiol

animals even allowed researchers to understand the kinetics of habituation [94]. Genetically induced cell death is also possible in worms through, for example, ectopic expression of a dominant version of the mec-4 allele, which encodes a subunit of a candidate mechanotransducing channel. Overexpression of mec-4-dominant allele is thought to elevate ion influx through the channel, leading to vacuolation of several cell types, including neurons and muscular cells [98]. Another example is use of light-inducible and tissueselective expression of mini singlet oxygen generator (miniSOG), a newly engineered protein that generates singlet oxygen upon blue light excitation, leading to cellular death without detectable damages to surrounding tissues [99]. More recently, laser ablation has emerged as an excellent tool to study the process of neuronal regeneration. Using high-energy pulses, it is possible to severe axons (axotomy) and then perform subsequent regeneration studies [100, 101].

Pioneering techniques such as optogenetics have also been employed in worms with great success [102-104]. First, by manipulating the release of acetylcholine or GABA at the NMJ using targeted expression of channel rhodopsin2 , researchers were capable of analyzing neurotransmission with high temporal precision $[105,106]$. Later, researchers developed a new system that allows manipulation of neural activity with high spatial and temporal resolution, enabling control of locomotion in real time [107]. Further expansion of this technique by combination with microfluidics technology and computer automation was developed in order to reach higher throughput and improve standardization and consistency in data gathering. In addition, it is possible to infuse drugs during optogenetic manipulations using microfluidics, providing a significant contribution for the study of synaptic function, for example [106]. Other opsins, namely, archaerhodopsin-3, a neuronal silencer, were recently applied in the study of the $C$. elegans nervous system [108].

Recently, a high-throughput microfluidic approach has been used for automatic identification and sorting of $C$. elegans mutants with possible neurodevelopmental or neurodegenerative phenotypes by using a GFP marker for GABAergic motor neurons, with impressive speed and efficacy [109].

\section{C. elegans in the Study of Human Disorders}

Despite its evolutionary distance from mammals, C. elegans possesses thousands of genes orthologous to humans [110]. Worms have allowed insight into molecular mechanisms underlying neurodegenerative disorders such as tauopathies [111, 112], Alzheimer's disease [113-115], Parkinson's disease [116, 117], polyglutamine disorders [118-122], juvenile neurolipofuscinosis [123], and amyotrophic lateral sclerosis [124], among others [125]. Most of the models involve transgenic expression of the human protein containing the mutation in specific tissues/neurons. For example, overexpression of an expanded polyglutamine tract in C. elegans neurons induces protein aggregation in vivo, and selective neuronal toxicity and motility defects $[118,126]$, equivalent to humans and mouse models. Panneuronal expression of mutated tau caused progressive motor uncoordination and accumulation of insoluble hyperphosphorylated tau in C. elegans. These animals presented substantial neurodegeneration, with axonal disruption and presynaptic defects $[112,126]$. This model was later used to mechanistically dissect tau-induced neurodegeneration and to identify drugs/genes that inhibit tau toxicity $[111,127-130]$.

Reverse genetics is another way of dissecting the biological role of a given gene and to better understand how loss of function mutations originates specific neuronal deficits. Mutations in presenilin genes cause one form of aggressive familial Alzheimer's disease. The two worm orthologous genes, sel-12 and hop-1, are required for correct morphology and function of two cholinergic neurons involved in temperature memory formation [115]. Interestingly, insertion of the wild type human gene, but not a mutated form, is able to revert neuronal deficits and memory impairment, suggesting an overlapping function between worm and human counterparts [115].

However, this remarkable resemblance of the model with the human picture is not always obvious. In humans, mutations in either PKD1 or PKD2 genes cause almost indistinguishable clinical symptoms, leading to polycystic kidney disease (PKD). Mice PKD models develop cysts in the kidney and other organs, similarly to humans. Deletion of worm orthologous genes, lov-1 and $p k d-2$, provided apparently discrepant and unrelated outcomes. No differences were found in the very rudimentary excretory system of $C$. elegans mutants; rather, lov-1 mutation affected mating behavior in male worms [131]. This mating defect was due to dysfunctional cilia, and amazingly, later findings have shown that PKD proteins were expressed in cilia of kidney cells and that cilliar dysfunction could be responsible for the formation of cysts [132]. Whereas at first glance the findings in worms were odd, they certainly contributed to the understanding of the biological process underlying PKD. These results are quite interesting in the light of recent evidence suggesting that many human neurodevelopmental problems are linked to mutations in primary cilia formation (ciliopaties) [133], making C. elegans an appealing model to study the molecular basis of these disorders.

In fact and apart from being a great model to study the mechanisms of neurodegeneration, worms are very appealing in the study of neurodevelopment disorders such as 
epilepsy, ID, and ASDs, considering the existing know-how of neuronal connectivity in this animal. Whereas environment can play a fundamental role in development of these disorders, numerous studies have shown that they have a strong genetic basis, with either monogenic or polygenic etiology. However, though various genetic studies pinpointed specific regions associated with these disorders, the functional validation of the findings has often been neglected. In fact, for a large proportion of the genes found to be associated with epilepsy, ID, and ASDs, nothing is known about their function or consequences of their mutation in the nervous system. $C$. elegans could be envisaged as an appealing biological platform, and the argument that $C$. elegans is too simple and limited in the behavioral repertoire to study these complex disorders is being abandoned in the light of evidence previously discussed. First, C. elegans displays complex behaviors such as learning and habit formation and even presents some degree of social interaction; second, the neurotransmitters/receptors and the basis of neuronal mechanisms are remarkably conserved, and thus, the neurobiological basis of human disease can be explored in detail in this model. In the next section, we will give some insights on emerging worm models in the study of the molecular mechanisms underlying epilepsy, ASDs, and ID.

\section{C. elegans as a Model to Study Epilepsy}

Epilepsy is estimated to affect 1-2\% of the population worldwide, and around $40 \%$ of the cases are thought to have a genetic basis. Epilepsy is characterized by repeated seizures (or convulsions), which are episodes of disturbed brain activity, i.e., abnormal, excessive, or hypersynchronous neuronal activity in the brain. Mutations in several genes have been linked to different types of epilepsy, including many genes that code for protein subunits of either voltage-gated or ligand-gated ion channels [134-136]. Numerous genetically engineered mice/rats have been developed to study epilepsy and to better understand the contribution of specific genetic mutations for the development of the disease [137-142].

Other cases of idiopathic-generalized epilepsy are compatible with a multigenic mode of inheritance and are most likely the result of additive interaction of multiple susceptibility genes contributing to disease. However and although every year several genetic associations are reported, most lack biological/functional validation. This flaw is a consequence of the high cost, in terms of money and time, of creating novel genetically modifiable murine mutant models for each gene. In this context, simpler and genetically amenable animal models such as worms are essential tools in dissection of gene function and contribute to the understanding of phenotype(s)/genotype relationships (Table 2).
Seizures are caused by an unbalance in either the excitatory and/or inhibitory input. In this context, simplicity of the $C$. elegans locomotor circuit may be crucial in studying seizure susceptibility. Whereas cholinergic innervation excites muscles to contract alternately on the ventral or dorsal side, it simultaneously activates GABAergic inhibition to relax muscles on the opposite side. Wild type worms do not naturally display seizures, but null mutants for unc-43, a calcium/calmodulin-dependent serine/threonine kinase II (CaMKII) that regulates synaptic plasticity, were reported to present spontaneous convulsions [143].

Somehow contradictory to the evidence in rodents, researchers found that wild type animals are resistant to GABA(A) receptor antagonist Pentylenetetrazol (PTZ), a potent compound that induces seizures in mammals. However, in specific sensitized genetic backgrounds, PTZ can produce different types of convulsions, depending on molecules and circuits affected. For example, unc-25 (GABA synthesis) mutants display repetitive contractions in the head, while unc-43 mutants present full-body convulsions (Fig. 2) [143]. The definitive proof of concept for the use of $C$. elegans to study epilepsy is the confirmation that the epilepticlike phenotype was a result of the abnormal synchronous activity of specific neurons. Using calcium imaging, researchers found that $u n c-43$ animals displayed aberrant intestinal calcium oscillations that were reflected in abnormal defecation rhythm [144], raising the hypothesis that the same could occur in neurons, increasing susceptibility to seizures.

A mutation (gain of function) in a neuronal acetylcholine receptor, acr-2, causes spontaneous muscle convulsions in C. elegans due to cholinergic overexcitation accompanied with a decreased GABAergic inhibition in the locomotor circuit [145]. Mutations in human acetylcholine receptors have also been associated with epilepsy [146]. Additional studies have shown that this epilepsylike phenotype is dependent on the activity of the TRPM nonselective cation channel gtl-2, which plays a role in ion homeostasis. Researchers have suggested that the convulsions were the result of a local ionic imbalance [145] and that glt-2 loss of function could counterweigh the excitation-inhibition imbalance caused by acr-2 (rather than affecting basal synaptic transmission), probably through ion level modification. In further support of this hypothesis, they show that altering $\mathrm{Zn}^{2+}$ homeostasis (but no $\mathrm{Mg}^{2+}$ ), had an anticonvulsant effect, analogously to glt-2 loss of function. These promising and groundbreaking results may be translated into the human picture, since: (1) TRPM channels from other species also show permeability to divalent cations, including $\mathrm{Zn}^{2+}$ [147], and (2) manipulation of $\mathrm{Zn}^{2+}$ can activate acetylcholine receptors while inhibiting some GABA receptors $[148,149]$. This study revealed a new role for ion homeostasis in seizure susceptibility and highlighted 
Mol Neurobiol

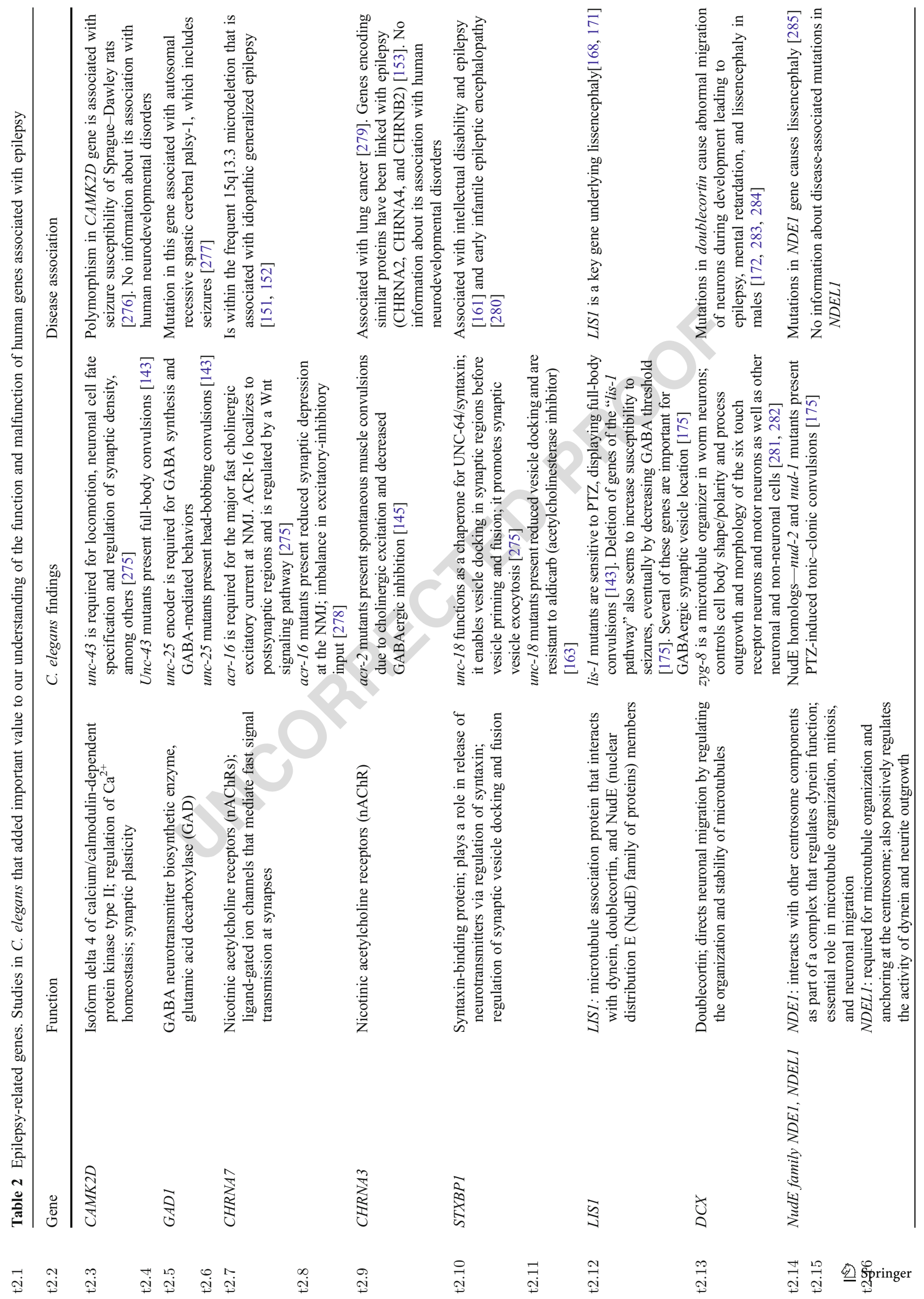




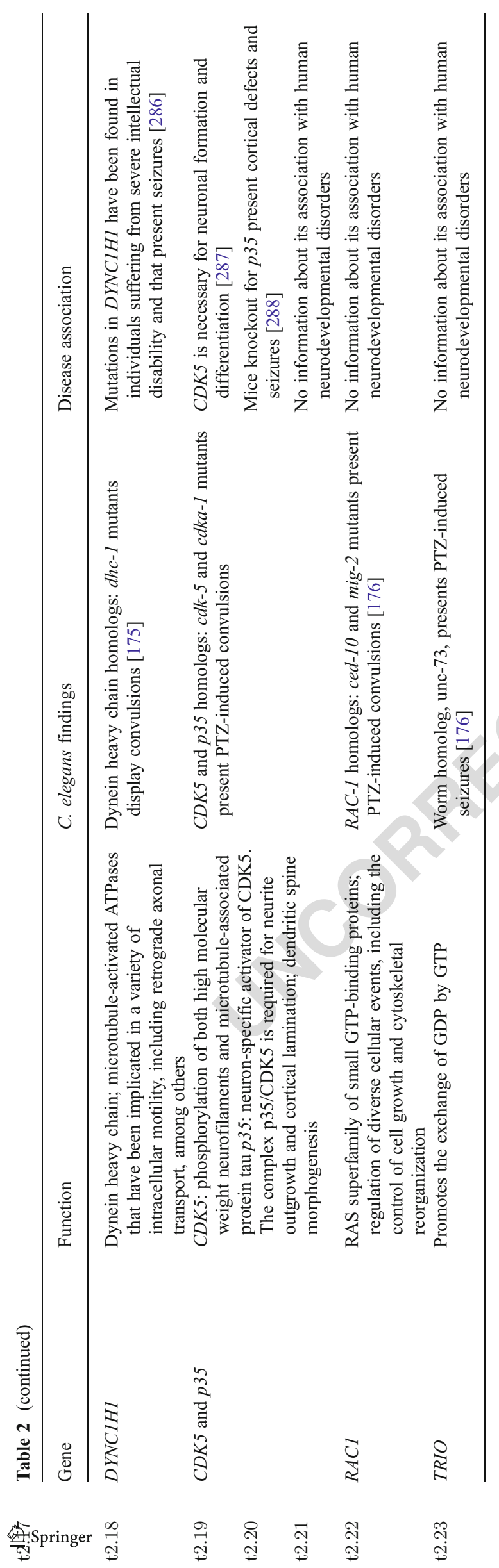

TRPM channels as new players in this process, which can now be further explored in higher organisms and eventually used to develop novel pharmacological approaches.

Another study has shown that increasing temperature in combination with exposure to higher levels of salts $(\mathrm{NaCl}$ and $\mathrm{MgCl}_{2}$ ) triggers abnormal neuronal bursts in C. elegans. Baccoside A, a molecule found in extracts of the plant Bacopa monnieri, which has been shown to inhibit excitatory neurotransmission by blockade of calcium channels, significantly reduced seizure/convulsion at higher temperatures, eventually by modulating calcium entry in the cells [150]. Moreover, T-type $\mathrm{Ca}^{2+}$ channel mutant $c c a-1$ does not present seizures at any stage, suggesting that additional studies are required to dissect how this molecule works and the contribution of these channels for epilepsy.

The CHRNA7 gene encodes the subunit alpha 7 of nicotinic acetylcholine receptors (nAChRs), members of a superfamily of ligand-gated ions mediating fast signal transmission at synapses. CHRNA7 has been associated with several neurodevelopmental disorders, namely, epilepsy, ID, and schizophrenia [151, 152]. CHRNA7 is a very strong candidate gene for epilepsy involvement, as genes encoding other subunits of nAChRs, e.g., CHRNA2, CHRNA4, and $C H R N B 2$, are known to be associated with autosomaldominant nocturnal frontal lobe epilepsy [153]. C. elegans possesses one of the largest nAChR families known for any organism and a combination of genetic, microarray, physiological, and reporter gene expression studies has added greatly to our understanding of the components of nematode muscle and neuronal nAChR subtype [154]. The C. elegans ortholog of CHRNA7 is acr-16 [155, 156], which encodes a similar subunit and works as a ligand-gated ion channel that is required for the major fast cholinergic excitatory current at C. elegans NMJ [157]. One elegant study has shown that in the NJM, one single stimulus is able to induce prominent long-lasting depression in acetylcholine motor neurons. This phenomenon is highly dependent on desensitization of the postsynaptic acetylcholine nicotinic receptor ACR-16 but not on its counterpart acetylcholine levamisole receptor UNC-38 [158]. Acr-16 mutants presented slower synaptic depression in comparison with wild type animals, suggesting that acr-16 plays a key role in the balance of excitatory and inhibitory inputs. Interestingly, similarities between worm and human nAChRs go beyond receptor function. The conserved Wnt pathway seems to be crucial for correct translocation of some types of nAChR into the pre- or postsynaptic membranes. In mammals, Wnt7a regulates presynpatic localization of $\alpha 7$-nAChRs [158]. Likewise, in worms, Wnt ligand CWN-2 binds to CAM-1/LIN-17 (Ror receptor tyrosine kinase/Frizzled) heteromeric receptors, activating downstream effector DSH-1 (disheveled), which regulates ACR-16 translocation into the postsynaptic membrane [159]. Mutants of all of these players present 
accumulation of nonsynaptic ACR-16 and a significant reduction in synaptic current (Fig. 3b). However and despite this evidence suggesting altered excitatory-inhibitory synaptic balance, it remains to be determined if these mutants present enhanced seizure susceptibility.

STXBP1 (syntaxin-binding protein 1) encodes a neuronal specific syntaxin-binding protein, the mammalian homolog of the C. elegans unc-18 gene [160]. Mutations in STXBP1 have been found to lead to autosomal dominant epilepsy and ID [161]. The C. elegans unc-18 gene was first identified as being required for maintenance of acetylcholine levels [162]. Unc-18 is required for neurotransmitter release and regulation of vesicle exocytosis via SNARE interaction (Fig. 3a) [163, 164]. Accordingly, worms lacking functional unc-18 show resistance to paralysis induced by aldicarb, an acetylcholinesterase inhibitor [15]. This mechanism is evolutionarily conserved, and as has been shown for unc-18,
STXPB1 also binds to syntaxin-1, a SNARE protein involved in synaptic vesicle docking and fusion, and seems to act in the control of vesicle docking as well as the regulation of the vesicle fusion rate $[165,166]$. In addition, it has previously been shown that mice lacking Munc18-1 suffer from complete loss of neurotransmitter release from synaptic vesicles throughout development [167]. Aldicarb resistance can suggest a different neuronal excitability in these mutants, which would be interesting to explore in the context of seizure susceptibility.

Lissencephaly is a nervous system disorder characterized by a "smooth brain," lacking convolutions or gyri due to abnormal neuronal migration and poor survival of cortical neurons during development. Lissencephaly can be caused by mutations in the TUBAIA, LISI, ARX, DCX, and RELN genes [168-174], among others, and several point mutations in these genes have been identified; importantly, patients

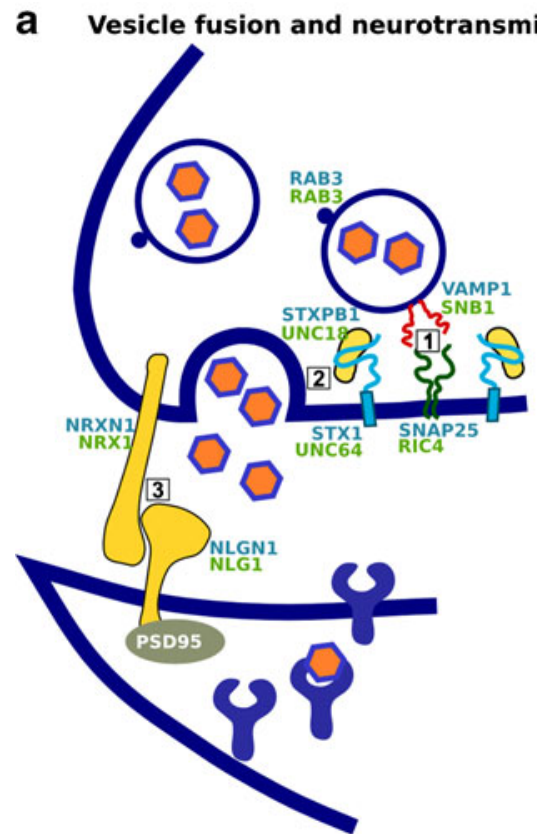

post-synaptic

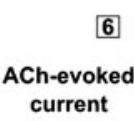

Fig. 3 Conserved neuronal pathways between C. elegans and humans, which are relevant in the context of different neurodevelopmental disorders. a At the presynaptic site, the conserved SNARE complex mediates vesicle fusion and neurotransmitter release to the synaptic cleft (1). STXPB1 (UNC-18 ortholog) binds to the SNARE protein STX1 (UNC-64 ortholog) (2) regulating this process. Mutations in STXPB1 are associated with epilepsy and intellectual disability. NLG-1 and NRX-1 are the C. elegans orthologs of neuroligins and neurexins, which are conserved cell adhesion proteins essential for synapse formation, maturation, and stability (3), and have been implicated in autism spectrum disorders. b Representative scheme of a cholinergic synapse between a motor neuron and a muscle cell in $C$. elegans. The translocation of nicotinic acetylcholine (ACh) receptors (nAChRs) may require conserved members of the Wnt signaling pathway in worms and humans. In C. elegans, CWN-2 (Wnt ligand; Wnt5 ortholog) binds to CAM-1/LIN-17 heteromeric receptors (1) (CAM-1: Ror receptor tyrosine kinase ortholog; LIN-17: frizzled ortholog), which activate downstream signal transduction molecule DSH-1

\section{b Wnt Signaling and nAChR translocation}
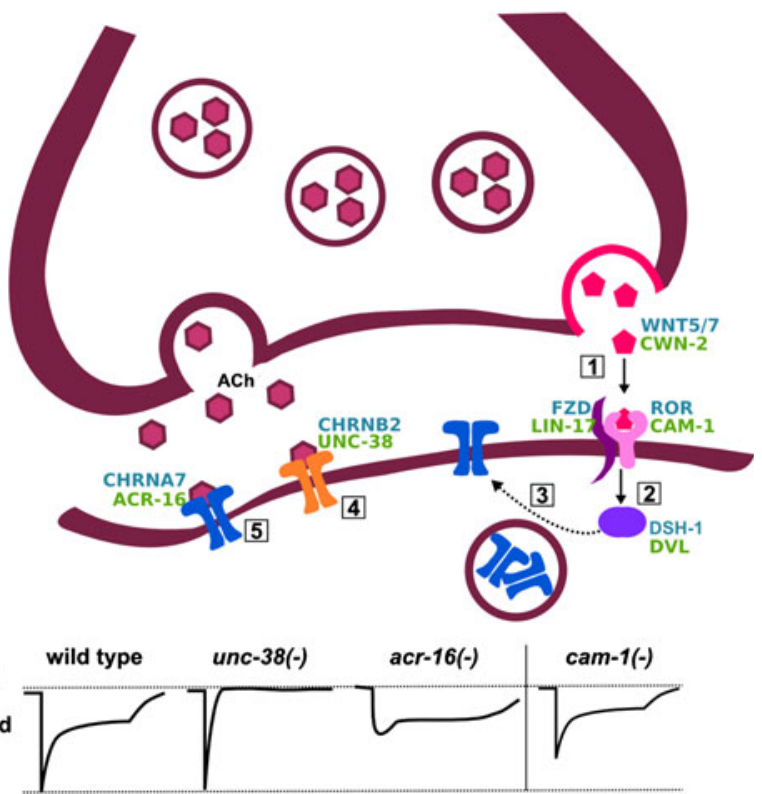

(disheveled (DVL) ortholog) (2). This pathway is necessary for correct translocation of nAChR ACR-16 to the postsynaptic synapse (3). Mutants for all of these genes present a reduction in synaptic current (6) (an example of an ACh-evoked current in cam-1(-) is shown). This Wnt-dependent translocation pathway seems to be conserved in humans, since Wnt7 is required for presynaptic localization of nACHRs in hippocampal neurons. ACh binds to either levamisoletype receptor UNC-38 (4) (ortholog of CHRNB2) or to nicotinic-type receptor ACR-16 (5) (ortholog of CHRNA7). 6 ACh induces rapid and complete desensitization of nicotinic ACR-16 receptors (unc-38(-); acr-16(+)), whereas its effect in levamisole UNC-38 receptors is less pronounced (acr-16(-);unc-38(+)). This is translated into faster and slower synaptic depression in $u n c-38$ and acr-16 mutants, respectively. This disturbance of excitatory-inhibitory balance may increase seizure susceptibility in worms. In humans, several mutations in different nAChRs have been associated with epilepsy. Human genes are depicted in blue and worm orthologs in green. [151-153, 158, 159, 161, 182-184, 186, 278, 280] 
often suffer from intractable epilepsy. C. elegans lis-1 mutants present more than $70 \%$ of lethality, and the survivors present marked seizure susceptibility when exposed to PTZ [143], which works by lowering a threshold of GABAergic response, revealing sensitized neuronal states, which would otherwise not manifest in normal conditions. No major defects were observed in neuronal architecture, but severe presynaptic defects in GABAergic vesicle distribution were found in these mutants [143]. Later studies have analyzed mutants for other genes of the lis-1 pathway and identified further "seizure-sensitive" genetic backgrounds [175].

LIS-1 interacts with dynein, a well-characterized motor protein, regulator of microtubules and involved in vesicle and organelle transport. Considering the fact that integrity of neural cytoskeleton is essential for regulation of intrinsic neuronal activity, it is not so surprising that dynein mutants also present enhanced PTZ sensitivity [175]. Likewise, mutants for Rac GTPases, actin polymerization regulators, demonstrated a robust behavioral response to PTZ and also exhibited hypersensitivity to aldicarb (an acetylcholinesterase inhibitor), suggesting a deficit in inhibitory neurotransmission [176]. Aldicarb causes body paralysis, resulting from accumulation of acetylcholine at the NMJ; hence, mutations that reduce synaptic transmission cause resistance to aldicarb and vice versa. Another study has identified several endocrine molecules and kinases that regulate GABA transmission in worms, which inactivation increased activity of body muscles, which is directly controlled by GABAergic neurons [15]. Of the 90 positive candidate genes, 21 had previously been associated with seizures, reflecting the value of this model in the study of seizure susceptibility [15].

Treating seizure-susceptible strains with antiepileptic compounds would go in further support of the use of $C$. elegans in the study of epilepsy. However, pharmacological results in C. elegans in this regard are not so straightforward to interpret. Anticonvulsants such as valproic acid, ethosuximide, or trimethadione, significantly extend the life span of C. elegans [177, 178], a peculiar phenotype that is not easily translatable to the human context. Interestingly, combined treatment of animals with valproic acid and trimethadione produced an additive effect in longevity, suggesting different signaling pathways, and suggested that modulation of neuronal activity may control longevity signals [177]. Indeed, these compounds modulate neuronal activity in worms, since it was found that trimethadione treatment caused hypersensitivity to aldicarb, indicative of neuromuscular activity stimulation [178]. We believe that the studies about the effects of these drugs in C. elegans can go beyond behavioral evaluation. For example, valproic acid functions as a histone deacetylase inhibitor and has been exploited in the context of several pathologies, including cancer. By doing a cross-species functional genomic approach and in an attempt to improve therapeutic efficacy of this drug, Forthun et al. have identified novel conserved sensitizers and synthetic lethal interactors of valproic acid [179]. A similar approach could be employed to identify seizure susceptibility/resilience pathways.

Studies with proconvulsant drugs have originated findings that are more straightforward to analyze. PTZ is able to elicit seizures in genetically sensitive backgrounds. Moreover, levamisole, known to activate neuronal nAChRs, which is able to provoke seizures in mammals [180, 181], induces hypercontracted paralysis of wild type nematodes, usually followed by relaxation and death.

\section{Worms and Social Behavior: Relevance for the Study of Autism Spectrum Disorders}

ASDs comprise a range of conditions, sometimes classified as pervasive developmental disorders, which involve one or more of the following characteristics: (1) abnormal social behavior, (2) deficits in communication, and (3) presence of stereotyped and repetitive behaviors and obsession with routines (DSM-IV). Due to inherent complexity of ASD symptoms, the use of C. elegans as a model system to study this group of disorders is controversial. However, since altered neuronal migration/connectivity or deficits in synaptic transmission has been proposed to be at the basis of etiology of numerous cases of ASDs, even if C. elegans does not fully recapitulate core symptoms of ASDs, it can still be very useful to dissect neuronal events leading to these conditions (Table 3 ).

Mutations in genes encoding neuroligin, neurexin, and shank proteins alter synaptic function and have been reported to underpin ID and ASDs [182-186]. Neuroligins are postsynaptic cell adhesion proteins that bind specifically to presynaptic proteins called neurexins (Fig. 3a). Both are present in excitatory and inhibitory synapses and are crucial for correct neuronal network formation and synapse maturation, stability, and transmission. C. elegans nrx-1 and $n l g-1$ genes are orthologous to human NRXN1 and $N L G N 1$ genes, respectively, with the corresponding proteins presenting similar functional domains [187, 188]. NGL-1 is expressed in a subset of neurons, and neuroligin-deficient mutants are viable, with no overt phenotype. However, these animals are defective in a subset of sensory behaviors and sensory processing and are hypersensitive to oxidative stress and mercury compounds [188-190]. Difficulties with processing and/or integration of sensory inputs are often part of the presentation of ASDs, though no sensory deficits have been recognized officially [191]. In this context, it is particularly interesting that $n \lg -1$ mutants have deficits in the processing of conflicting sensory inputs, as measured in an 
Mol Neurobiol

t3.1 Table 3 Intellectual disability (ID)-related genes. Studies in C. elegans that added important value to our understanding of the function and malfunction of human genes associated with ID

Disease association

$A S P M$

May be involved in protein traffic between late Golgi and early endosomes

Dual-specificity tyrosine (Y) phosphorylation-regulated kinase $1 \mathrm{~A}$; suggested role in signaling pathways regulating cell proliferation and eventually brain development

DSCR1/RCAN1 Regulator of calcineurin 1; inhibits calcineurin-dependent transcription by binding to the catalytic domain of calcineurin A. Could play a role during central nervous system development

\section{t3.10 PQBP1} via association with the transcription machinery
ASPM-1 binds to LIN-15 and is required for its correct localization in the spindle poles. aspm- 1 mutants present pleiotropic phenotypes suggesting that this gene is required for other cell types besides neurons [229]

F29B9.2 has a similar function as the human counterpart and its knockdown leads to uncoordination [238]

alr-1 mutants present deficits in the differentiation of a GABAergic neuron; alr-1 acts through LIM1 homolog lin11 pathway. It controls the expression of target genes such as mec-3 to ensure touch receptor neuron differentiation [240, 289, 290]

tba- 1 mutants are viable: compensatory mechanism, since this mutation is lethal in combination with other tubulin gene mutations. Animals display neuronal synaptic deficits and axonal misguidance [242]

pad-1 suppression showed embryonic lethality. Most of the tissues of the embryo failed to undergo proper patterning during gastrulation; incomplete morphogenesis did not occur [244]

$m b k-1$ nulls are viable, contrary to mammals. However, overexpression of this gene leads to dose-dependent olfactory defects [250]. These defects were reverted by normalizing $m b k-1$ expression, highlighting a possible therapeutic possibility

$\mathrm{RCN}-1$ has a similar function as the human counterpart. $r c n-1$ deletion or overexpression leads to similar phenotype, including defects in growth, fertility, cuticle development, and egg laying. Importantly, normalization of $\mathrm{rcn}$ 1 expression rescues the deficits [258]

$p q b p-1.1$ is necessary for lipid metabolism. No major neuronal phenotype [262] activation of transcription directly or

\footnotetext{
Alpha-thalassemia/mental retardation syndrome X-linked; contains an ATPase/helicase domain; SWI/SNF family of chromatin-remodeling proteins. Potential involvement in the gene regulation at interphase and chromosomal segregation in mitosis
}

No report regarding xnp-1 mutant neurological phenotype. $x n p-1$ is vital for gonadal development [267, 268]

Associated with autosomal recessive primary microcephaly [227]

Associated with X-linked ID and cleft lip/palate [235]

Associated with epilepsy and ID [239]

Associated with lissencephaly and polymicrogyria [173, 241]

Present in the Down syndrome critical region [243]

Present in the Down syndrome critical region [243]. Clinical trials with the aim of normalizing DYRK1A function are underway

Present in the Down syndrome critical region [243]

Mutations in this gene have been found in patients with Renpenning's syndrome 1 and other syndromes with X-linked mental retardation $[260,261]$. Patients present a lean body, which can be related to worm alterations in lipid metabolism

Associated with alpha-thalassemia/ mental retardation syndrome X-linked [264-266]. Patients present gonadal abnormalities, similar to worm mutant strains approach-avoidance paradigm. $n l g-1$ mutants respond normally to the volatile attractant diacetyl and the repellent cupric acetate; however, their response to simultaneous presentation of these two cues is clearly defective [190].
In further support of a similar role of mammalian and nematode proteins were the results showing that expression of human or rat neuroligin in $n l g-1$ mutants rescues osmotic avoidance and gentle touch response phenotypes. 
Remarkably, expression of mutant human proteins (with previously identified mutations in ASDs patients) did not revert behavioral impairments nor did expression of wild type NGL-1 under the control of muscular promoter [188], suggesting a key role for this protein in neuronal function.

One unexpected result in C. elegans was the fact that loss of neuroligin was not merely correlated with increased sensitivity to oxidative stress but actually caused oxidative stress [190]. Though there is no concluding evidence that oxidative stress may be involved in neurobiology of ASDs, some recent evidence shows that autistic patients present a significant elevation in oxidative stress biomarkers and reduced serum antioxidants such as transferrin and ceruloplasmin [192]. C. elegans NRX-1, ortholog of neurexin, is expressed in most of the neurons and localizes to presynaptic specializations [193]. Contrary to $n g l-1$ mutants, $n r x-1$ nulls do not present any major phenotype or deficits in osmotic avoidance, but interestingly, mutations in this gene suppress neuroligin deficits [187].

The shank gene family encodes postsynaptic proteins that function as part of the NMDA receptor-associated PSD-95 complex (Fig. 3a) [194]. In mammals, Shank cooperates with Homer protein to induce accumulation of inositol1,4,5-trisphosphate (IP3) receptors in dendritic spines and formation of putative multisynapse spines [195]. Recently, mutations in Shank genes have been implicated in ASDs [185], suggesting an important role in normal cognitive development. Overexpression of ShanklB and Homerlb in hippocampal neurons induces spine maturation, including translocation of the intracellular $\mathrm{Ca}^{2+}$ channel inositol trisphosphate receptor (IP3R) [196]. The nematode shn-1 gene is the ortholog of vertebrate Shankl. RNAi of shn-1 did not cause lethality or major developmental abnormalities. However and in the same line of evidence of mammalian data, suppression of shn-1 in a defective IP3R background resulted in animals with altered defecation rhythm [197], suggesting a possible role of this protein in affecting function of IP3R. Additional characterization of two different mutant alleles for $s h n-1$ revealed a crucial role for the ANKrepeat domain in $\mathrm{Ca}^{2+}$ signaling with IP3R [198]. It would be interesting to analyze these strains regarding $\mathrm{Ca}+$ signaling and size and strength of synapses considering the fact that Shankl knockout mice present reduced size of dendritic spines and weaker basal synaptic transmission [199].

Neurobeachin (NBEA) has been identified as an autism candidate gene in a patient with a de novo chromosomal translocation [200]. This multidomain scaffolding protein has been suggested to be involved in neuronal post-Golgi membrane traffic with a role in neurotransmitter release and synaptic functioning [201-203]. Cellular knockdown of $N B E A$ suggested that this protein is a negative regulator of secretion of large dense-core vesicles [203]. Study of the $C$. elegans ortholog, sel-2, further supported this role in vesicle transport. Sel-2 was identified as a negative regulator of LIN-12/Notch activity [204], and members of the Notch pathway have also been shown to be modifiers of the NBEA homolog in Drosophila [205]. Deeper analysis of this interaction may contribute to better understanding of molecular events leading to a subset of ASDs due to deficits in vesicle formation.

L1CAMs are transmembranar cell adhesion receptors belonging to the immunoglobulin superfamily and are conserved in C. elegans. The mammalian L1CAM family is composed of four proteins: L1, CHL1, NrCAM, and neurofascin [206]. Mutations in L1 can originate the Xlinked neurological disorder, corpus callosum hypoplasia (CRASH, mental retardation, adducted thumbs, spastic paraplegia, and hydrocephalus) [207-209]. Latest evidence implicated a protein of this family, $\mathrm{NrCAM}$, in autism [210]. C. elegans has two L1CAM homologs, lad-2 and lad-1 (or sax-7) [211-214], which have distinct biological roles. While lad-2 expression is restricted to a few neurons, sax7 is widely expressed since embryonic stages [212, 213, 215]. LAD-2 is important for axon migration by anchoring MAB-20 (ortolog of semaphorin 2) to PLX-2 (ortolog of plexin) [215]. Concordantly, mammalian proteins also function as coreceptors for semaphorin-mediated axon pathfinding [216-218]. Despite involvement in the same pathway, lad-2 mutants have significantly more axonal defects than mab-20 or plx-2 mutants [215], suggesting that lad-2 may mediate axonal migration through another independent pathway, which could be interesting to ascertain in mammals. On the other hand, $\operatorname{sax}-7$ mutants present a "normal" development of the nervous system but display deficits in neuronal positioning [211-214], similarly to what is observed in L1 and CHL1 knockout mice [216, 218-221]. It is important to refer that L1CAMs are essential in mammals and flies but not in worms, providing a unique framework for the study of the biological role of these proteins.

Contrary to what was initially assumed, $C$. elegans exhibit a broad variety of social behaviors, including mutual attraction and aggregation, mating, population density sensing, and solitary- vs. group-feeding strategies. Variation in feeding strategy is solely due to a single amino acid substitution in NPY receptor, $n p r-1$ [72]. Solitary strains present high $n p r-1$ activity, whereas social strains display low activity. This receptor is particularly expressed in the RMG inter/motor neuron, the hub of a finely tuned pathway that controls aggregation and related behaviors [222]. No reports have directly implicated NPY receptors in ASDs, yet, there are some data that may corroborate this hypothesis. First, Drosophila NPY (dNFP) is involved in regulation of larval foraging and social behavior [223]. Second, NPY Y2 receptor-deficient male mice display an increase in social interaction [224]. Third, although not conclusive since several genes are within the affected region, there is at least one 
Mol Neurobiol

998 reported case of an autistic child with a deletion leading to 999 hemizygosity for genes encoding neuropeptide receptors 1000 NPY1R and NPY5R and for glutamine and glycine 1001 neurotransmitter receptor subunits (AMPA-2, GLRA3, and 1002 GLRB) [225]. Overall, these results seem to pinpoint NPY 1003 as an important modulator of social behavior in higher 1004 species as well, though more studies need to be performed 1005 to validate this theory.

1006 Memory and Learning in C. elegans: Insights 1007 into Intellectual Disability

1008 ID is one of the most frequent neurological impairments and 1009 is a very heterogeneous group of disorders. Increasing num1010 ber of genes identified over the last years associated with ID 1011 suggests that this phenotype can emerge as the final common 1012 pathway of many different types of abnormal cellular processes. 1013 Overall, it is considered that ID can stem from two broad 1014 mechanistic themes: dysfunction of neurodevelopmental pro1015 grams and alterations in synaptic organization and plasticity 1016 [226], both including cellular processes and molecular players 1017 present in C. elegans (Table 4).

1018 Autosomal recessive primary microcephaly (MCPH) is 1019 characterized by a severe ID and is known to be associated 1020 with mutations in several genes, among which is the ASPM 1021 [227]. In MCPH patient cells, ASPM has been shown to be 1022 required for correct organization and orientation of the mi1023 totic spindle and cytokinesis [228]. The C. elegans ortholog 1024 of this protein is ASPM-1, which binds to LIN-5 and is 1025 required for correct location of LIN-5 to meiotic and mitotic 1026 spindle poles [229]. LIN-5 is the ortholog of human $N u M A$ 1027 and belongs to the conserved pathway controlling spindle 1028 position [230]. Large-scale C. elegans RNAi experiments 1029 also indicate that aspm-1 is necessary for embryonic and 1030 larval viability, germline maintenance, vulval morphogene1031 sis, and locomotion [231-233], which may indicate that 1032 ASPM may be relevant for other types of cells. Indeed, very 1033 recent work showed that lack of functional ASPM was 1034 associated with loss of germ cells, both in testis and 1035 ovaries [234].

1036 The PHF8 gene, which encodes a histone demethylase, 1037 has been found to be mutated in several patients with $\mathrm{X}$ 1038 linked ID and cleft lip/palate [235, 236]. The zebrafish 1039 ortholog has been shown to regulate cell survival in the 1040 developing brain and to be involved in jaw development 1041 [237]. In C. elegans, the most closely related homolog is 1042 F29B9.2, which is expressed mainly in neuronal cells. Such 1043 as the human counterpart, F29B9.2 catalyzes demethylation 1044 of di- and monomethylated lysine 9 of histone H3 in vivo. 1045 F29B9.2 inactivation leads to a relatively mild phenotype 1046 in the form of uncoordinated locomotion [238], and 1047 pan-neuronal promoter, but not under a muscle promoter, rescued the phenotype associated with loss of F29B9.2.

The aristaless-related homeodomain protein ARX has been shown to underlie multiple forms of X-linked ID [239]. Arx knockout mice exhibit thinner cerebral cortices because of decreased neural precursor proliferation and also exhibit defects in differentiation and migration of GABAergic interneurons [169]. C. elegans ortholog, alr-1, acts in a pathway with the LIM1 ortholog lin-11 to regulate development of a subset of chemosensory neurons. Moreover, alr-1 mutants present deficits in differentiation of a GABAergic motoneuron, suggesting parallels with $A R X$ functions in vertebrates [240].

Mutations in TUBA1A gene have been associated with cortical dysgenesis such as lissencephaly and bilateral asymmetrical polymicrogyria $[173,241]$. In $C$. elegans, null alleles of the orthologous gene, $t b a-1$, do not present any major locomotor or neuronal defect, probably due to compensatory mechanisms, since this mutation is lethal in combination with other tubulin mutations [242]. However, interestingly, a gain-of-function mutation in $t b a-1$ leads to motor neuron synapse disruption and axonal defects [242], which is concordant with a role of this gene in the correct development of the nervous system. Analogously, (putatively) dominant mutations in human TUBA1A are associated with neuronal migration deficits and axonal malformation [170, 173].

Down syndrome is the most common form of ID worldwide, caused by a triplication of all or just a critical region of chromosome 21 , which leads to a very specific and welldefined phenotype. C21ORF5/DOPEY2 is one of the genes within the "Down Syndrome Critical Region," which are hypothesized to be responsible for majority of the phenotype [243]. Of notice, the first attempt to study Down syndrome-associated genes in $C$. elegans involved the DOPEY2 ortholog pad-1 [244]. Pad-1 was found to be necessary for proper patterning during gastrulation and morphogenesis. In the same line of evidence, overexpression of human DOPEY2 in mice leads to alterations in cortical layers together with behavioral impairment [245, 246].

Another gene putatively involved in Down syndrome is $D Y R K 1 A$, a member of the dual-specificity tyrosine phosphorylation-regulated kinase [247]. DYRK1A involvement in critical neuronal processes such as neurogenesis and neuronal differentiation has been widely studied using mice but also simpler organisms such as Drosophila and $C$. elegans [248, 249]. The C. elegans ortholog is $m b k-1$, but in contrast to vertebrate $D Y R K 1 A$ orthologs and the fly minibrain ortholog, lack of $m b k-1$ does not lead to any neuronal proliferation defects [250]. However, increased $m b k-1$ expression was shown to lead to dose-sensible specific functional olfactory defects. Remarkably, these defects were reversible by normalizing $m b k-1$ expression [250], 
t4.1 Table 4 Autism spectrum disorder (ASD)-related genes. Studies in C. elegans that added important value to our understanding of the function and malfunction of human genes associated with ASDs

\begin{tabular}{ll}
\hline Gene & Function \\
\hline $\begin{array}{l}\text { Neuroligins } \\
\text { NLGN3 NLGN4 }\end{array}$ & $\begin{array}{l}\text { Neuroligin family; cell adhesion } \\
\text { molecules present at the postsynaptic } \\
\text { side of the synapse and may be } \\
\text { essential for the formation of } \\
\text { functional synapses }\end{array}$
\end{tabular}

C. elegans findings

nlg-1 mutants have sensory processing deficits; hypersensitive to oxidative stress and mercury. These animals also present osmotic avoidance deficits and touch response phenotype $[188,190]$. Recent evidence suggests that $n \lg -1$ and nrx-1 mediate a retrograde synaptic signal that inhibits neurotransmitter release at $\mathrm{NMJ}$ $N R X 2 N R X 3$

SHANK1

Neuropeptide Y receptor; family of Gi/ o-protein-coupled receptors that mediate food intake, anxiety and stress response, and control of pituitary hormone release

\section{is required for efficient} neurotransmission; involved in the formation of synaptic contacts

Adapter protein in the postsynaptic density (PSD) of excitatory synapses; interconnects receptors including NMDA-type and metabotropic glutamate receptors via complexes with PSD-95 and Homer. Plays a role in the structural and functional organizations of the dendritic spine and synaptic junction

Neurobeachin; binds to type II regulatory subunits of protein kinase A and anchors/targets them to the membrane

Transmembrane cell adhesion molecule with an important role in the development of the nervous system; involved in neuron-neuron adhesion, neurite fasciculation, and outgrowth of neurites phenotype; however, mutations in this gene suppress neuroligin mutations [187]

shn-1 strain presents no overt phenotype; however, suppression of $s h n-1$ in a defective inositol-1,4,5-trisphosphate (IP3) receptor background alters defecation rhythm [197]. A key role for ANK repeat domain and PDZ in receptor [198]

sel-2 is a negative regulator of $\mathrm{LIN}-12$ / Notch activity; involved in vesicle secretion (?) [204]

LAD-2 is required for axonal migration, since it anchors MAB-20 (semaphorin) to PLX-2 (plexin) [215]. lad-2 mutants present severe axonal defects, which can partially be independent on the sempahorin/plexin pathway.

lad-1 (sax-7) strain presents pleiotropic phenotypes that include uncoordination, embryonic lethality, and deficits in neuronal positioning and axonal-misguided trajectories [212]

Activity of npr-1 is correlated with the degree of "socialization" [72, 291, 292]. Social and solitary strains differ naturally in the levels of NPR-1 protein nrx-1 mutants do not present observable regulating $\mathrm{Ca}^{2+}$-signaling with the IP3
Disease association

Mutations in these genes have been associated with ASDs [182-184]

Mutations in neurexin genes have been associated with ASDs [186]

Mutations in SHANK have been associated with ASDs [185]

Mutations associated with autism [200]

Mutations associated with CRASH [207-209]

No information about its association with human neurodevelopmental disorders. Yet, Drosophila NPY is involved in social behavior as well [223], and NPY2 receptor knockout mice present social abnormalities [224] which provided the first hint that DYRK1 induced deficits could be reversed in fully differentiated neurons. This possibility has been confirmed later in higher model organisms [251-253] and has set off several therapeutic approaches that are now being evaluated in human clinical trials (ClinicalTrials.gov identifier: NCT01394796; NCT01699711).

DSCR 1 is another gene residing in the Down Syndrome Critical Region [254]. DSCR1 is a known inhibitor of calcineurin-mediated signaling pathways [255], which are involved in multiple processes including neuronal plasticity [256] and neuronal development via NFAT signaling [257]. DSCR1, along with DYRK1A, is thought to downregulate
NFAT-mediated gene activation [247]. Calcineurin regulators seem to be evolutionarily conserved, and $C$. elegans possesses a sole DSCR1 homolog, rcn-1 [254, 258]. Analogous to DSCR 1, rcn-1 also inhibits calcineurin phosphatase activity via calcineurin A interaction. Moreover, worms overexpressing $r c n-1$ could reproduce multiple phenotypes of calcineurin loss-of-function mutants [258] providing an in vivo proof of $\mathrm{rcn}-1 /$ calcineurin regulation and giving further support as to the relation between DSCR1 overdosage and the phenotypes observed in DS.

Often, simple organisms do not replicate the complete phenotype spectra of human disorders. Still, they may allow studying and focusing on specific pathological features and 
Mol Neurobiol

1127 better understanding of protein function. This is the case of 1128 PQBP1 gene that when mutated is associated with a com1129 plex X-linked disorder, Renpenning's syndrome [259-261], 1130 characterized by ID and lean body build (OMIM \#309500). 1131 The C. elegans ortholog is $p q b p-1.1$ that, such as the human 1132 counterpart, encodes a protein with a polyglutamine-binding 1133 region in polar amino acid-rich domain, a WW domain 1134 also involved in regulation of transcription activity, and 1135 a C-terminal domain involved in the interaction with a 1136 spliceosome component [262]. Although pqbp-1.1 is 1137 expressed in few neurons, no neuronal phenotype was ob1138 served in $p q b p$-1.1-functional mutants. However, it was 1139 observed that lack of $p q b p-1.1$ leads to alterations in lipid 1140 metabolism shown by a reduction of triglycerides [262], 1141 which could be somehow related to lean body observed in 1142 human patients. Considering that the lipidic metabolic path1143 ways are fundamentally conserved between species, $C$. 1144 elegans could be a good model to study PQBP1-induced 1145 lipidic dysfunction and its effects in neurons.

1146

1147

1148

1149

1150

1151

1152

1153

1154

1155

1156

1157

1158

1159

1160

1161

1162

1163

\section{Insights on Other Neurodevelopmental Disorders}

1165 Disrupted-in-Schizophrenia 1 (DISC1) is a very well1166 established susceptibility gene for schizophrenia that also 1167 seems to be involved in other disorders such as ASD, 1168 depression, and bipolar disorder [269]. DISC1 protein has 1169 been thoroughly studied and is known to act as a scaffold 1170 protein, with multiple and diverse interacting partners, in1171 volved in neurodevelopmental and neurosignaling processes 1172 [270]. The C. elegans genome does not contain a DISC1 1173 ortholog. However, a heterologous strain expressing $1174 m$ DISC1 was useful to dissect the pathway by which DISC1 1175 may regulate axonal connections. Studies using this 1176 model showed that in motor neurons, DISC1 interacts with UNC-73/TRIO and activates RAC-PAK signaling to regulate axon guidance [271]. Interestingly, these pathways are conserved, and in mammals, it is known that TRIO regulates axon growth and guidance via RAC [272]. Furthermore, this heterologous C. elegans model may represent a good tool to identify new small molecules with therapeutic effects in modulating the TRIO-RAC pathway such as those that regulate axonal connectivity.

\section{From Genes to Therapies}

C. elegans represents a powerful tool to dissect cellular and molecular processes of human disorders and has emerged as an attractive platform in the context of large drug or genetic screenings due to its simplicity, low cost of cultivation, and small size that allows their growth on microtiter plates. Moreover, ease of genetic manipulation and commonality of several biological processes are both valuable in the geneto-drug and drug-to-gene discovery (nicely reviewed in [53]). If on one side, random mutagenesis can help in identification of novel gene targets conferring susceptibility or resistance to a specific group of drugs, large-scale drug screenings in specific genetic backgrounds may help dissect the mechanisms of drug action in normal and pathological conditions.

An elegant example is the identification of 185 aldicarbresistant mutants, among which were 132 genes that had not be previously associated with synaptic transmission. Of these, 24 encoded proteins that were localized to presynaptic specializations, and loss-of-function mutations in 12 genes caused defects in presynaptic structure [22].

Others have used transgenic worm models expressing the mutated human protein to perform both genetic and drug screenings. For example, Kraemer's lab has used a worm model of tauopathy to screen a drug library containing 1,120 molecules. They identified azaperone, a typical antipsychotic drug, as a robust modifier of motor deficits and levels of insoluble tau [128]. Suggesting common drug-acting pathways in worms and humans, azaperone was also effective in reducing tau aggregation in a human cell line. Remarkably, other drugs acting on dopamine receptor D2 such as flupenthixol, perphenazine, and zotepine were also effective in ameliorating tau-induced dysfunction in both models, suggesting D2 antagonism as a promising therapeutic strategy for tau neurotoxicity [128], a pathway that without C. elegans contribution would be unlikely to be discovered.

In another study, four different chemical libraries comprising 14,100 small membrane-permeable compounds were screened for induction of behavioral/morphological defects in wild type worms [273]. Three hundred eight molecules led to a variety of phenotypes, from simple motility deficits to severe morphological problems. However,
1186

1187

1188

1189

1190

1191

1192

1193

1194

1195

1196

1197

1198

1199

1200

1201

1202

1203

1204

1205

1206

1207

1208

1209

1210

1211

1212

1213

1214

1215

1216

1217

1218

1219

1220

1221

1222

1223

1224

1225

1226 
1227 despite this high-hit result for bioactivity of new drugs in $C$. 1228 elegans, an important consideration is the gap between 1229 worm and human mechanisms of drug absorption, distribu1230 tion, metabolism, excretion, or toxicity. Nevertheless, in this 1231 screen, researchers also discovered that a novel compound, 1232 which they named nemadipine-A, resembling a class of 1233 antihypertension drugs called the 1,4-dihydropyridines that 1234 antagonize the alpha 1-subunit of L-type calcium channels, 1235 induced robust defects in morphology and egg laying. They 1236 identified egl-19, the only L-type calcium channel alpha 11237 subunit in C. elegans, as the target gene in a genetic sup1238 pressor screening. Interestingly, the compound could also 1239 antagonize vertebrate L-type calcium channels, demonstrating 1240 that worms and mammals share a common target, despite 1241 originating divergent phenotypical outcomes.
Another example is the "hypothesis-free approach" screening of 900,000 small molecules that allowed identification of new classes of proteostasis regulators important in treatment of several conformational diseases such as polyglutamine disorders and Alzheimer's and Parkinson's diseases. Though some of these molecules acted via "canonical pathways" such as via HSF-1, FOXO, and NRF-2 and the chaperone machinery, the underlying mechanisms were distinct from previously identified smallmolecule activators of the heat shock response [274].

Not much has been done in the context of neurodevelopmental disorders regarding large-scale genetic and/or drug screening approaches. Several factors may contribute to this: first, neurodevelopmental disorders frequently encompass complex and difficult "scorable" phenotypes (e.g., neuronal migration defects or abnormal synaptic transmission) that restrain large-scale analysis methodology. Second, for several neurodevelopmental disorders, there is no unique drug or gene that modifies the phenotype satisfactorily due to their inherent complexity. Nevertheless, considering all pros and cons of using $C$. elegans in this type of screenings, we still believe that the strategy of using this model as the first line of research may lead to identification of novel and implausible drugs and/or cellular/molecular pathways of drug action that otherwise would be difficult to pinpoint. Yet, once a drug (gene?) is identified as potentially relevant in the context of a specific disorder in worms, additional studies need to be performed in higher organisms to fully validate it and exclude all side effects that it may have in the context of a more complex organism.

\section{Final Remarks}

The transparent worm C. elegans is one of the most powerful and versatile model organisms, enabling elucidation of several cellular and molecular mechanisms underlying neuronal function and dysfunction. Due to easiness of genetic manipulation and similarity with vertebrate neuronal molecular pathways, this organism can be used to functionally validate genetic associations identified in neurodevelopmental disorders. Moreover, since $C$. elegans is amenable to highthroughput genetic and drug screenings, it is an excellent biological platform for drug identification and clarification of signaling pathways involved in novel therapeutic interventions.

Acknowledgments The authors would like to acknowledge Fundaçãopara a Ciência e Tecnologia (FCT) (PTDC/SAU-GMG/ $112577 / 2009)$. CB is a recipient of a postdoctoral fellowship from FCT.

\section{References}

1. Bessa, C.L., F; Maciel, P, Molecular genetics of intellectual disability, InTech, Editor 2012

2. Abrams TW (2012) Studies on aplysia neurons suggest treatments for chronic human disorders. Curr Biol 22(17):R705-11

3. Gatto CL, Broadie K (2011) Drosophila modeling of heritable neurodevelopmental disorders. Curr Opin Neurobiol 21(6):834 41

4. Kabashi E et al (2010) In the swim of things: recent insights to neurogenetic disorders from zebrafish. Trends Genet 26(8):37381

5. Wormbook. Available from: http://www.wormbook.org/

6. Wormatlas. Available from: http://www.wormatlas.org/

7. Bono MD, Villu Maricq A (2005) Neuronal substrates of complex behaviors in C. elegans. Annu Rev Neurosci 28(1):451-501

8. Chalfie M et al (1994) Green fluorescent protein as a marker for gene expression. Science 263(5148):802-5

9. Hobert O, Loria P (2006) Uses of GFP in Caenorhabditis elegans. Methods Biochem Anal 47:203-26

10. White JG et al (1986) The structure of the nervous system of the nematode Caenorhabditis elegans. Philos Trans R Soc Lond B Biol Sci 314(1165):1-340

11. Jin, Y., Synaptogenesis. WormBook, 2005: p. 1-11

12. Nonet ML (1999) Visualization of synaptic specializations in live C. elegans with synaptic vesicle protein-GFP fusions. J Neurosci Methods 89(1):33-40

13. Dittman JS, Kaplan JM (2006) Factors regulating the abundance and localization of synaptobrevin in the plasma membrane. Proc Natl Acad Sci USA 103(30):11399-404

14. Jin Y et al (1999) The Caenorhabditis elegans gene unc-25 encodes glutamic acid decarboxylase and is required for synaptic transmission but not synaptic development. J Neurosci 19(2):539-48

15. Vashlishan AB et al (2008) An RNAi screen identifies genes that regulate GABA synapses. Neuron 58(3):346-361

16. Zhen M, Jin Y (1999) The liprin protein SYD-2 regulates the differentiation of presynaptic termini in C. elegans. Nature 401(6751):371-5

17. Yeh E et al (2005) Identification of genes involved in synaptogenesis using a fluorescent active zone marker in Caenorhabditis elegans. J Neurosci 25(15):3833-41

18. Stigloher C et al (2011) The presynaptic dense projection of the Caenorhabditis elegans cholinergic neuromuscular junction localizes synaptic vesicles at the active zone through SYD2/liprin and UNC-10/RIM-dependent interactions. J Neurosci 31(12):4388-96 
Mol Neurobiol

1337

1338

1339

1340

1341

1342

1343

1344

1345

1346

1347

1348

1349

1350

1351

1352

1353

1354

1355

1356

1357

1358

1359

1360

1361

1362

1363

1364

1365

1366

1367

1368

1369

1370

1371

1372

1373

1374

1375

1376

1377

1378

1379

1380

1381

1382

1383

1384

1385

1386

1387

1388

1389

1390

1391

1392

1393

1394

1395

1396

1397

1398

1399

1400

1401

1402
19. Hall DH, Russell RL (1991) The posterior nervous system of the nematode Caenorhabditis elegans: serial reconstruction of identified neurons and complete pattern of synaptic interactions. $\mathrm{J}$ Neurosci 11(1):1-22

20. Zhao H, Nonet ML (2000) A retrograde signal is involved in activity-dependent remodeling at a $C$. elegans neuromuscular junction. Development 127(6):1253-66

21. Rand, J.B., Acetylcholine. WormBook, 2007: p. 1-21

22. Sieburth D et al (2005) Systematic analysis of genes required for synapse structure and function. Nature 436(7050):510-7

23. Brockie PJ et al (2001) Differential expression of glutamate receptor subunits in the nervous system of Caenorhabditis elegans and their regulation by the homeodomain protein UNC42. J Neurosci 21(5):1510-22

24. Brockie, P.J. and A.V. Maricq, Ionotropic glutamate receptors: genetics, behavior and electrophysiology. WormBook, 2006: p. $1-16$

25. Brockie PJ, Maricq AV (2003) Ionotropic glutamate receptors in Caenorhabditis elegans. Neurosignals 12(3):108-25

26. Cully DF et al (1994) Cloning of an avermectin-sensitive glutamate-gated chloride channel from Caenorhabditis elegans. Nature 371(6499):707-11

27. Avery L (1993) The genetics of feeding in Caenorhabditis elegans. Genetics 133(4):897-917

28. Lee RY et al (1999) EAT-4, a homolog of a mammalian sodiumdependent inorganic phosphate cotransporter, is necessary for glutamatergic neurotransmission in Caenorhabditis elegans. J Neurosci 19(1):159-67

29. Rankin CH, Wicks SR (2000) Mutations of the Caenorhabditis elegans brain-specific inorganic phosphate transporter eat-4 affect habituation of the tap-withdrawal response without affecting the response itself. J Neurosci 20(11):4337-44

30. Rose JK, Kaun KR, Rankin CH (2002) A new group-training procedure for habituation demonstrates that presynaptic glutamate release contributes to long-term memory in Caenorhabditis elegans. Learn Mem 9(3):130-7

31. Lee D et al (2008) Human vesicular glutamate transporters functionally complement EAT-4 in C. elegans. Mol Cells 25(1):50-4

32. Morrison GE, van der Kooy D (2001) A mutation in the AMPAtype glutamate receptor, glr-1, blocks olfactory associative and nonassociative learning in Caenorhabditis elegans. Behav Neurosci 115(3):640-9

33. Chase, D.L. and M.R. Koelle, Biogenic amine neurotransmitters in C. elegans. WormBook, 2007: p. 1-15

34. Chase DL, Pepper JS, Koelle MR (2004) Mechanism of extrasynaptic dopamine signaling in Caenorhabditis elegans. Nat Neurosci 7(10):1096-103

35. Cao S et al (2005) Torsin-mediated protection from cellular stress in the dopaminergic neurons of Caenorhabditis elegans. $\mathrm{J}$ Neurosci 25(15):3801-12

36. Marvanova M, Nichols CD (2007) Identification of neuroprotective compounds of Caenorhabditis elegans dopaminergic neurons against 6-OHDA. J Mol Neurosci 31(2):127-37

37. Nass R, Blakely RD (2003) The Caenorhabditis elegans dopaminergic system: opportunities for insights into dopamine transport and neurodegeneration. Annu Rev Pharmacol Toxicol 43:521-44

38. Jorgensen, E.M., Gaba. WormBook, 2005: p. 1-13

39. Beg AA, Jorgensen EM (2003) EXP-1 is an excitatory GABAgated cation channel. Nat Neurosci 6(11):1145-52

40. Bamber BA et al (2005) The composition of the GABA receptor at the Caenorhabditis elegans neuromuscular junction. $\mathrm{Br} \mathrm{J}$ Pharmacol 144(4):502-9

41. Bamber BA, Twyman RE, Jorgensen EM (2003) Pharmacological characterization of the homomeric and heteromeric UNC-49 GABA receptors in C. elegans. Br J Pharmacol 138(5):883-93
42. Schuske K, Beg AA, Jorgensen EM (2004) The GABA nervous system in C. elegans. Trends Neurosci 27(7):407-14

43. Li, C. and K. Kim, Neuropeptides. WormBook, 2008: p. 1-36

44. Pierce SB et al (2001) Regulation of DAF-2 receptor signaling by human insulin and ins-1, a member of the unusually large and diverse C. elegans insulin gene family. Genes Dev 15(6):672-86

45. Li W, Kennedy SG, Ruvkun G (2003) daf-28 encodes a $C$. elegans insulin superfamily member that is regulated by environmental cues and acts in the DAF-2 signaling pathway. Genes Dev 17(7):844-58

46. Clancy DJ et al (2001) Extension of life-span by loss of CHICO, a Drosophila insulin receptor substrate protein. Science 292(5514):104-6

47. Tatar M et al (2001) A mutant Drosophila insulin receptor homolog that extends life-span and impairs neuroendocrine function. Science 292(5514):107-10

48. Holzenberger M et al (2003) IGF-1 receptor regulates lifespan and resistance to oxidative stress in mice. Nature 421(6919):1827

49. Choy RK, Kemner JM, Thomas JH (2006) Fluoxetine-resistance genes in Caenorhabditis elegans function in the intestine and may act in drug transport. Genetics 172(2):885-92

50. Choy RK, Thomas JH (1999) Fluoxetine-resistant mutants in $C$. elegans define a novel family of transmembrane proteins. Mol Cell 4(2):143-52

51. Weinshenker D, Garriga G, Thomas JH (1995) Genetic and pharmacological analysis of neurotransmitters controlling egg laying in C. elegans. J Neurosci 15(10):6975-85

52. Ward A et al (2009) Cocaine modulates locomotion behavior in C. elegans. PLoS One 4(6):e5946

53. Artal-Sanz M, de Jong L, Tavernarakis N (2006) Caenorhabditis elegans: a versatile platform for drug discovery. Biotechnol J 1(12):1405-18

54. Culotti JG, Russell RL (1978) Osmotic avoidance defective mutants of the nematode Caenorhabditis elegans. Genetics 90(2):243-56

55. Wheeler JM, Thomas JH (2006) Identification of a novel gene family involved in osmotic stress response in Caenorhabditis elegans. Genetics 174(3):1327-36

56. Hart AC et al (1999) Distinct signaling pathways mediate touch and osmosensory responses in a polymodal sensory neuron. $\mathrm{J}$ Neurosci 19(6):1952-8

57. Bargmann CI, Horvitz HR (1991) Chemosensory neurons with overlapping functions direct chemotaxis to multiple chemicals in C. elegans. Neuron 7(5):729-42

58. Sambongi $\mathrm{Y}$ et al (2000) Caenorhabditis elegans senses protons through amphid chemosensory neurons: proton signals elicit avoidance behavior. NeuroReport 11(10):2229-32

59. Zhang Y, Lu H, Bargmann CI (2005) Pathogenic bacteria induce aversive olfactory learning in Caenorhabditis elegans. Nature 438(7065):179-84

60. Apfeld J, Kenyon C (1999) Regulation of lifespan by sensory perception in Caenorhabditis elegans. Nature 402(6763):804-9

61. Libert S et al (2007) Regulation of Drosophila life span by olfaction and food-derived odors. Science 315(5815):1133-7

62. Steidl S, Rose JK, Rankin CH (2003) Stages of memory in the nematode Caenorhabditis elegans. Behav Cogn Neurosci Rev 2(1):3-14

63. Lin, C.H. and C.H. Rankin, Nematode learning and memory: neuroethology, in Encyclopedia of animal behavior, D.B. Editors-in-Chief:Michael and M. Janice, Editors. 2010, Academic: Oxford. p. 520-526

64. Mohri A et al (2005) Genetic control of temperature preference in the nematode Caenorhabditis elegans. Genetics 169(3):1437-50

65. Wen JY et al (1997) Mutations that prevent associative learning in C. elegans. Behav Neurosci 111(2):354-68
1403 
1469

1470

1471

1472

1473

1474

1475

1476

1477

1478

1479

1480

1481

1482

1483

1484

1485

1486

1487

1488

1489

1490

1491

1492

1493

1494

1495

1496

1497

1498

1499

1500

1501

1502

1503

1504

1505

1506

1507

1508

1509

1510

1511

1512

1513

1514

1515

1516

1517

1518

1519

1520

1521

1522

1523

1524

1525

1526

1527

1528

1529

1530

1531

1532

1533

1534
66. Hukema RK et al (2006) Antagonistic sensory cues generate gustatory plasticity in Caenorhabditis elegans. EMBO J 25(2):312-22

67. Jansen G, Weinkove D, Plasterk RH (2002) The G-protein gamma subunit gpc-1 of the nematode $C$. elegans is involved in taste adaptation. EMBO J 21(5):986-94

68. Mori I, Ohshima Y (1995) Neural regulation of thermotaxis in Caenorhabditis elegans. Nature 376(6538):344-8

69. Saeki S, Yamamoto M, Iino Y (2001) Plasticity of chemotaxis revealed by paired presentation of a chemoattractant and starvation in the nematode Caenorhabditis elegans. J Exp Biol 204(Pt 10):1757-64

70. Rose JK et al (2003) GLR-1, a non-NMDA glutamate receptor homolog, is critical for long-term memory in Caenorhabditis elegans. J Neurosci 23(29):9595-9

71. Beck CD, Rankin CH (1997) Long-term habituation is produced by distributed training at long ISIs and not by massed training or short ISIs in Caenorhabditis elegans. Anim Learn Behav 25(4):446-457

72. de Bono M, Bargmann CI (1998) Natural variation in a neuropeptide $\mathrm{Y}$ receptor homolog modifies social behavior and food response in C. elegans. Cell 94(5):679-689

73. Lin S, Boey D, Herzog H (2004) NPY and Y receptors: lessons from transgenic and knockout models. Neuropeptides 38(4):189200

74. Thorsell A et al (2006) The effects of social isolation on neuropeptide Y levels, exploratory and anxiety-related behaviors in rats. Pharmacol Biochem Behav 83(1):28-34

75. Aydin C, Oztan O, Isgor C (2011) Effects of a selective Y2R antagonist, JNJ-31020028, on nicotine abstinence-related social anxiety-like behavior, neuropeptide $\mathrm{Y}$ and corticotropin releasing factor mRNA levels in the novelty-seeking phenotype. Behav Brain Res 222(2):332-41

76. Timmons L, Court DL, Fire A (2001) Ingestion of bacterially expressed dsRNAs can produce specific and potent genetic interference in Caenorhabditis elegans. Gene 263(1-2):103-12

77. Simmer F et al (2002) Loss of the putative RNA-directed RNA polymerase RRF-3 makes $C$. elegans hypersensitive to RNAi. Curr Biol 12(15):1317-9

78. Esposito G et al (2007) Efficient and cell specific knock-down of gene function in targeted C. elegans neurons. Gene 395(1-2):170-6

79. Tavernarakis $\mathrm{N}$ et al (2000) Heritable and inducible genetic interference by double-stranded RNA encoded by transgenes. Nat Genet 24(2):180-3

80. Kerr R et al (2000) Optical imaging of calcium transients in neurons and pharyngeal muscle of $C$. elegans. Neuron 26(3):583-94

81. Kuhara A et al (2008) Temperature sensing by an olfactory neuron in a circuit controlling behavior of $C$. elegans. Science 320(5877):803-7

82. Nishida Y et al (2011) Identification of the AFD neuron as the site of action of the CREB protein in Caenorhabditis elegans thermotaxis. EMBO Rep 12(8):855-62

83. Schafer, W.R., Neurophysiological methods in C. elegans: an introduction. WormBook, 2006: p. 1-4

84. Francis MM, Mellem JE, Maricq AV (2003) Bridging the gap between genes and behavior: recent advances in the electrophysiological analysis of neural function in Caenorhabditis elegans. Trends Neurosci 26(2):90-9

85. Nonet ML et al (1998) Synaptic transmission deficits in Caenorhabditis elegans synaptobrevin mutants. J Neurosci 18(1):70-80

86. Dent JA, Davis MW, Avery L (1997) avr-15 encodes a chloride channel subunit that mediates inhibitory glutamatergic neurotransmission and ivermectin sensitivity in Caenorhabditis elegans. EMBO J 16(19):5867-79
87. Nickell WT et al (2002) Single ionic channels of two Caenorhabditis elegans chemosensory neurons in native membrane. J Membr Biol 189(1):55-66

88. O'Hagan R, Chalfie M, Goodman MB (2005) The MEC-4 DEG/ $\mathrm{ENaC}$ channel of Caenorhabditis elegans touch receptor neurons transduces mechanical signals. Nat Neurosci 8(1):43-50

89. Richmond JE, Jorgensen EM (1999) One GABA and two acetylcholine receptors function at the $C$. elegans neuromuscular junction. Nat Neurosci 2(9):791-7

90. Mellem JE et al (2002) Decoding of polymodal sensory stimuli by postsynaptic glutamate receptors in $C$. elegans. Neuron 36(5):933-44

91. Goodman MB et al (1998) Active currents regulate sensitivity and dynamic range in C. elegans neurons. Neuron 20(4):763-72

92. Lockery SR, Goodman MB (1998) Tight-seal whole-cell patch clamping of Caenorhabditis elegans neurons. Methods Enzymol 293:201-17

93. Wicks SR, Rankin CH (1995) Integration of mechanosensory stimuli in Caenorhabditis elegans. J Neurosci 15(3 Pt 2):2434-44

94. Wicks SR, Rankin CH (1996) The integration of antagonistic reflexes revealed by laser ablation of identified neurons determines habituation kinetics of the Caenorhabditis elegans tap withdrawal response. J Comp Physiol A 179(5):675-85

95. Chung SH et al (2006) The role of the AFD neuron in C. elegans thermotaxis analyzed using femtosecond laser ablation. BMC Neurosci 7:30

96. Kimura KD et al (2004) The C. elegans thermosensory neuron AFD responds to warming. Curr Biol 14(14):1291-5

97. Chalfie $\mathrm{M}$ et al (1985) The neural circuit for touch sensitivity in Caenorhabditis elegans. J Neurosci 5(4):956-64

98. Harbinder S et al (1997) Genetically targeted cell disruption in Caenorhabditis elegans. Proc Natl Acad Sci USA 94(24):13128-33

99. Qi YB et al (2012) Photo-inducible cell ablation in Caenorhabditis elegans using the genetically encoded singlet oxygen generating protein miniSOG. Proc Natl Acad Sci USA 109(19):7499-504

100. Byrne, A.B., T.J. Edwards, and M. Hammarlund, In vivo laser axotomy in C. elegans. J Vis Exp, 2011(51)

101. Hammarlund $M$ et al (2009) Axon regeneration requires a conserved MAP kinase pathway. Science 323(5915):802-6

102. Zhang $F$ et al (2007) Multimodal fast optical interrogation of neural circuitry. Nature 446(7136):633-9

103. Li W et al (2011) The neural circuits and sensory channels mediating harsh touch sensation in Caenorhabditis elegans. Nat Commun 2:315

104. Lindsay TH, Thiele TR, Lockery SR (2011) Optogenetic analysis of synaptic transmission in the central nervous system of the nematode Caenorhabditis elegans. Nat Commun 2:306

105. Liewald JF et al (2008) Optogenetic analysis of synaptic function. Nat Methods 5(10):895-902

106. Stirman JN et al (2010) High-throughput study of synaptic transmission at the neuromuscular junction enabled by optogenetics and microfluidics. J Neurosci Methods 191(1):90-3

107. Leifer AM et al (2011) Optogenetic manipulation of neural activity in freely moving Caenorhabditis elegans. Nat Methods $8(2): 147-52$

108. Okazaki A, Sudo Y, Takagi S (2012) Optical silencing of $C$. elegans cells with arch proton pump. PLoS One 7(5):e35370

109. Caceres Ide C et al (2012) Laterally orienting C. elegans using geometry at microscale for high-throughput visual screens in neurodegeneration and neuronal development studies. PLoS One 7(4):e35037

110. Shaye DD, Greenwald I (2011) OrthoList: a compendium of $C$. elegans genes with human orthologs. PLoS One 6(5):e20085

111. Kraemer BC et al (2006) Molecular pathways that influence human tau-induced pathology in Caenorhabditis elegans. Hum Mol Genet 15(9):1483-96
1535 
1601

1602

1603

1604

1605

1606

1607

1608

1609

1610

1611

1612

1613

1614

1615

1616

1617

1618

1619

1620

1621

1622

1623

1624

1625

1626

1627

1628

1629

1630

1631

1632

1633

1634

1635

1636

1637

1638

1639

1640

1641

1642

1643

1644

1645

1646

1647

1648

1649

1650

1651

1652

1653

1654

1655

1656

1657

1658

1659

1660

1661

1662

1663

1664

1665

1666
112. Kraemer BC et al (2003) Neurodegeneration and defective neurotransmission in a Caenorhabditis elegans model of tauopathy. Proc Natl Acad Sci USA 100(17):9980-5

113. Levitan D et al (1996) Assessment of normal and mutant human presenilin function in Caenorhabditis elegans. Proc Natl Acad Sci USA 93(25):14940-4

114. Link CD et al (2003) Gene expression analysis in a transgenic Caenorhabditis elegans Alzheimer's disease model. Neurobiol Aging 24(3):397-413

115. Wittenburg $\mathrm{N}$ et al (2000) Presenilin is required for proper morphology and function of neurons in C. elegans. Nature 406(6793):306-9

116. Hamamichi S et al (2008) Hypothesis-based RNAi screening identifies neuroprotective genes in a Parkinson's disease model. Proc Natl Acad Sci USA 105(2):728-33

117. Vartiainen $S$ et al (2006) Identification of gene expression changes in transgenic C. elegans overexpressing human alphasynuclein. Neurobiol Dis 22(3):477-86

118. Teixeira-Castro A et al (2011) Neuron-specific proteotoxicity of mutant ataxin-3 in C. elegans: rescue by the DAF-16 and HSF-1 pathways. Hum Mol Genet 20(15):2996-3009

119. Faber PW et al (1999) Polyglutamine-mediated dysfunction and apoptotic death of a Caenorhabditis elegans sensory neuron. Proc Natl Acad Sci USA 96(1):179-84

120. Satyal SH et al (2000) Polyglutamine aggregates alter protein folding homeostasis in Caenorhabditis elegans. Proc Natl Acad Sci USA 97(11):5750-5

121. Rodrigues AJ et al (2007) Functional genomics and biochemical characterization of the $C$. elegans orthologue of the MachadoJoseph disease protein ataxin-3. FASEB J 21(4):1126-36

122. Rodrigues AJ et al (2009) ATX-3, CDC-48 and UBXN-5: a new trimolecular complex in Caenorhabditis elegans. Biochem Biophys Res Commun 386(4):575-81

123. de Voer $\mathrm{G}$ et al (2005) Deletion of the Caenorhabditis elegans homologues of the CLN3 gene, involved in human juvenile neuronal ceroid lipofuscinosis, causes a mild progeric phenotype. J Inherit Metab Dis 28(6): 1065-80

124. Oeda $\mathrm{T}$ et al (2001) Oxidative stress causes abnormal accumulation of familial amyotrophic lateral sclerosis-related mutant SOD1 in transgenic Caenorhabditis elegans. Hum Mol Genet 10(19):2013-23

125. Baumeister R, Ge L (2002) The worm in us-Caenorhabditis elegans as a model of human disease. Trends Biotechnol 20(4):147-8

126. Miyasaka $\mathrm{T}$ et al (2005) Progressive neurodegeneration in $C$. elegans model of tauopathy. Neurobiol Dis 20(2):372-83

127. Fatouros $\mathrm{C}$ et al (2012) Inhibition of tau aggregation in a novel Caenorhabditis elegans model of tauopathy mitigates proteotoxicity. Hum Mol Genet 21(16):3587-603

128. McCormick, A.V., et al., Dopamine D2 receptor antagonism suppresses tau aggregation and neurotoxicity. Biol Psychiatry, 2012

129. Guthrie CR, Schellenberg GD, Kraemer BC (2009) SUT-2 potentiates tau-induced neurotoxicity in Caenorhabditis elegans. Hum Mol Genet 18(10):1825-38

130. Kraemer BC, Schellenberg GD (2007) SUT-1 enables tau-induced neurotoxicity in C. elegans. Hum Mol Genet 16(16):1959-71

131. Barr MM, Sternberg PW (1999) A polycystic kidney-disease gene homologue required for male mating behaviour in $C$. elegans. Nature 401(6751):386-9

132. Igarashi P, Somlo S (2002) Genetics and pathogenesis of polycystic kidney disease. J Am Soc Nephrol 13(9):2384-98

133. Lee JE, Gleeson JG (2011) Cilia in the nervous system: linking cilia function and neurodevelopmental disorders. Curr Opin Neurol 24(2):98-105

134. Hirose S et al (2005) Genetics of idiopathic epilepsies. Epilepsia 46(Suppl 1):38-43
135. Lu Y, Wang X (2009) Genes associated with idiopathic epilepsies: a current overview. Neurol Res 31(2):135-43

136. Noebels JL (2003) Exploring new gene discoveries in idiopathic generalized epilepsy. Epilepsia 44(Suppl 2):16-21

137. Kash SF et al (1997) Epilepsy in mice deficient in the $65-\mathrm{kDa}$ isoform of glutamic acid decarboxylase. Proc Natl Acad Sci USA 94(25):14060-5

138. Kearney JA et al (2006) Severe epilepsy resulting from genetic interaction between Scn2a and Kcnq2. Hum Mol Genet 15(6):1043-8

139. Noebels JL, Sidman RL (1979) Inherited epilepsy: spike-wave and focal motor seizures in the mutant mouse tottering. Science 204(4399):1334-6

140. Smart SL et al (1998) Deletion of the K(V)1.1 potassium channel causes epilepsy in mice. Neuron 20(4):809-19

141. Zhang X et al (2010) Deletion of the potassium channel Kv12.2 causes hippocampal hyperexcitability and epilepsy. Nat Neurosci 13(9):1056-8

142. Khosravani H, Zamponi GW (2006) Voltage-gated calcium channels and idiopathic generalized epilepsies. Physiol Rev 86(3):941-66

143. Williams SN et al (2004) Epileptic-like convulsions associated with LIS-1 in the cytoskeletal control of neurotransmitter signaling in Caenorhabditis elegans. Hum Mol Genet 13(18):2043-59

144. Nehrke K, Denton J, Mowrey W (2008) Intestinal Ca2+ wave dynamics in freely moving C. elegans coordinate execution of a rhythmic motor program. Am J Physiol Cell Physiol 294(1): C333-44

145. Stawicki TM et al (2011) TRPM channels modulate epileptic-like convulsions via systemic ion homeostasis. Curr Biol 21(10):883-8

146. Steinlein OK et al (1995) A missense mutation in the neuronal nicotinic acetylcholine receptor alpha 4 subunit is associated with autosomal dominant nocturnal frontal lobe epilepsy. Nat Genet 11(2):201-3

147. Monteilh-Zoller MK et al (2003) TRPM7 provides an ion channel mechanism for cellular entry of trace metal ions. J Gen Physiol 121(1):49-60

148. Hsiao B, Dweck D, Luetje CW (2001) Subunit-dependent modulation of neuronal nicotinic receptors by zinc. J Neurosci 21(6): $1848-56$

149. Smart TG, Hosie AM, Miller PS (2004) Zn2+ ions: modulators of excitatory and inhibitory synaptic activity. Neuroscientist 10(5):432-42

150. Pandey R et al (2010) Baccoside A suppresses epileptic-like seizure/convulsion in Caenorhabditis elegans. Seizure 19(7):439-442

151. Dibbens LM et al (2009) Familial and sporadic 15q13.3 microdeletions in idiopathic generalized epilepsy: precedent for disorders with complex inheritance. Hum Mol Genet 18(19):3626-3631

152. Helbig I et al (2009) $15 \mathrm{q} 13.3$ microdeletions increase risk of idiopathic generalized epilepsy. Nat Genet 41(2):160-162

153. Steinlein OK, Bertrand D (2008) Neuronal nicotinic acetylcholine receptors: from the genetic analysis to neurological diseases. Biochem Pharmacol 76(10):1175-1183

154. Brown LA et al (2006) Contributions from Caenorhabditis elegans functional genetics to antiparasitic drug target identification and validation: Nicotinic acetylcholine receptors, a case study. Int J Parasitol 36(6):617-624

155. Ballivet $M$ et al (1996) Nicotinic acetylcholine receptors in the nematode Caenorhabditis elegans. J Mol Biol 258(2):261-269

156. Mongan NP et al (1998) An extensive and diverse gene family of nicotinic acetylcholine receptor alpha subunits in Caenorhabditis elegans. Recept Channels 6(3):213-228

157. Francis MM et al (2005) The Ror receptor tyrosine kinase CAM1 is required for ACR-16-mediated synaptic transmission at the C. elegans neuromuscular junction. Neuron 46(4):581-594
1667

1668

1669

1670

1671

1672

1673

1674

1675

1676

1677

1678

1679

1680

1681

1682

1683

1684

1685

1686

1687

1688

1689

1690

1691

1692

1693

1694

1695

1696

1697

1698

1699

1700

1701

1702

1703

1704

1705

1706

1707

1708

1709

1710

1711

1712

1713

1714

1715

1716

1717

1718

1719

1720

1721

1722

1723

1724

1725

1726

1727

1728

1729

1730

1731

1732 
1733

1734

1735

1736

1737

1738

1739

1740

1741

1742

1743

1744

1745

1746

1747

1748

1749

1750

1751

1752

1753

1754

1755

1756

1757

1758

1759

1760

1761

1762

1763

1764

1765

1766

1767

1768

1769

1770

1771

1772

1773

1774

1775

1776

1777

1778

1779

1780

1781

1782

1783

1784

1785

1786

1787

1788

1789

1790

1791

1792

1793

1794

1795

1796

1797

1798
158. Farias GG et al (2007) Wnt-7a induces presynaptic colocalization of alpha 7-nicotinic acetylcholine receptors and adenomatous polyposis coli in hippocampal neurons. J Neurosci 27(20):5313-25

159. Jensen $M$ et al (2012) Wnt signaling regulates acetylcholine receptor translocation and synaptic plasticity in the adult nervous system. Cell 149(1):173-87

160. Pevsner J, Hsu SC, Scheller RH (1994) n-Sec1: a neural-specific syntaxin-binding protein. Proc Natl Acad Sci U S A 91(4):14451449

161. Hamdan FF et al (2009) De novo STXBP1 mutations in mental retardation and nonsyndromic epilepsy. Ann Neurol 65(6): $748-753$

162. Gengyo-Ando K et al (1993) The C. elegans unc-18 gene encodes a protein expressed in motor neurons. Neuron 11(4):703-711

163. Weimer RM et al (2003) Defects in synaptic vesicle docking in unc-18 mutants. Nat Neurosci 6(10):1023-1030

164. McEwen JM, Kaplan JM (2008) UNC-18 promotes both the anterograde trafficking and synaptic function of syntaxin. Mol Biol Cell 19(9):3836-3846

165. Wu MN et al (1999) Syntaxin 1A interacts with multiple exocytic proteins to regulate neurotransmitter release in vivo. Neuron 23(3):593-605

166. Gerber SH et al (2008) Conformational switch of syntaxin-1 controls synaptic vesicle fusion. Science (New York, NY) 321(5895):1507-1510

167. Verhage $M$ et al (2000) Synaptic assembly of the brain in the absence of neurotransmitter secretion. Science 287(5454):864869

168. Dobyns WB et al (1993) Lissencephaly. A human brain malformation associated with deletion of the LIS1 gene located at chromosome 17p13. JAMA 270(23):2838-42

169. Kitamura $\mathrm{K}$ et al (2002) Mutation of ARX causes abnormal development of forebrain and testes in mice and X-linked lissencephaly with abnormal genitalia in humans. Nat Genet 32(3):359-69

170. Kumar RA et al (2010) TUBA1A mutations cause wide spectrum lissencephaly (smooth brain) and suggest that multiple neuronal migration pathways converge on alpha tubulins. Hum Mol Genet 19(14):2817-2827

171. Pilz DT et al (1998) LIS1 and XLIS (DCX) mutations cause most classical lissencephaly, but different patterns of malformation. Hum Mol Genet 7(13):2029-37

172. Sossey-Alaoui K et al (1998) Human doublecortin (DCX) and the homologous gene in mouse encode a putative $\mathrm{Ca} 2+-$ dependent signaling protein which is mutated in human X-linked neuronal migration defects. Hum Mol Genet 7(8):1327-32

173. Jaglin XH, Chelly J (2009) Tubulin-related cortical dysgeneses: microtubule dysfunction underlying neuronal migration defects. Trends Genet 25(12):555-66

174. Hong SE et al (2000) Autosomal recessive lissencephaly with cerebellar hypoplasia is associated with human RELN mutations. Nat Genet 26(1):93-6

175. Locke CJ et al (2006) Genetic interactions among cortical malformation genes that influence susceptibility to convulsions in C. elegans. Brain Res 1120(1):23-34

176. Locke CJ et al (2009) Pharmacogenetic analysis reveals a postdevelopmental role for Rac GTPases in Caenorhabditis elegans GABAergic neurotransmission. Genetics 183(4):1357-1372

177. Evason K et al (2008) Valproic acid extends Caenorhabditis elegans lifespan. Aging Cell 7(3):305-17

178. Evason K et al (2005) Anticonvulsant medications extend worm life-span. Science 307(5707):258-62

179. Forthun RB et al (2012) Cross-species functional genomic analysis identifies resistance genes of the histone deacetylase inhibitor valproic acid. PLoS One 7(11):e48992
180. Palcoux JB, Niaudet P, Goumy P (1994) Side effects of levamisole in children with nephrosis. Pediatr Nephrol 8(2):263-4

181. Joly C et al (1998) Acute levamisole poisoning. Presse Med 27(15):717

182. Jamain S et al (2003) Mutations of the X-linked genes encoding neuroligins NLGN3 and NLGN4 are associated with autism. Nat Genet 34(1):27-9

183. Laumonnier $\mathrm{F}$ et al (2004) X-linked mental retardation and autism are associated with a mutation in the NLGN4 gene, a member of the neuroligin family. Am J Hum Genet 74(3):552-7

184. Yan J et al (2008) Analysis of the neuroligin $4 \mathrm{Y}$ gene in patients with autism. Psychiatr Genet 18(4):204-7

185. Sato D et al (2012) SHANK1 deletions in males with autism spectrum disorder. Am J Hum Genet 90(5):879-87

186. Kim HG et al (2008) Disruption of neurexin 1 associated with autism spectrum disorder. Am J Hum Genet 82(1):199-207

187. Calahorro F, Ruiz-Rubio M (2011) Caenorhabditis elegans as an experimental tool for the study of complex neurological diseases: Parkinson's disease, Alzheimer's disease and autism spectrum disorder. Invertebr Neurosci 11(2):73-83

188. Calahorro F, Ruiz-Rubio M (2012) Functional phenotypic rescue of Caenorhabditis elegans neuroligin-deficient mutants by the human and rat NLGN1 genes. PLoS One 7(6):e39277-e39277

189. Calahorro, F., E. Alejandre, and M. Ruiz-Rubio, Osmotic avoidance in Caenorhabditis elegans: synaptic function of two genes, orthologues of human NRXN1 and NLGN1, as candidates for autism. J Vis Exp, 2009(34)

190. Hunter JW et al (2010) Neuroligin-deficient mutants of $C$. elegans have sensory processing deficits and are hypersensitive to oxidative stress and mercury toxicity. Dis Model Mech $3(5-6): 366-376$

191. Filipek PA et al (2000) Practice parameter: screening and diagnosis of autism: report of the Quality Standards Subcommittee of the American Academy of Neurology and the Child Neurology Society. Neurology 55(4):468-79

192. Chauhan A, Chauhan V (2006) Oxidative stress in autism. Pathophysiology 13(3):171-81

193. Haklai-Topper L et al (2011) The neurexin superfamily of Caenorhabditis elegans. Gene Expr Patterns 11(1-2):144-50

194. Naisbitt $S$ et al (1999) Shank, a novel family of postsynaptic density proteins that binds to the NMDA receptor/PSD-95/GKAP complex and cortactin. Neuron 23(3):569-82

195. Sala C et al (2001) Regulation of dendritic spine morphology and synaptic function by Shank and Homer. Neuron 31(1):115-30

196. Sala C et al (2005) Key role of the postsynaptic density scaffold proteins Shank and Homer in the functional architecture of $\mathrm{Ca} 2+$ homeostasis at dendritic spines in hippocampal neurons. J Neurosci 25(18):4587-92

197. Jee C et al (2004) SHN-1, a Shank homologue in C. elegans, affects defecation rhythm via the inositol-1,4,5-trisphosphate receptor. FEBS Lett 561(1-3):29-36

198. Oh WC et al (2011) ANK repeat-domain of SHN-1 Is indispensable for in vivo SHN-1 function in C. elegans. Mol Cells 31(1):79-84

199. Hung AY et al (2008) Smaller dendritic spines, weaker synaptic transmission, but enhanced spatial learning in mice lacking Shank1. J Neurosci 28(7):1697-708

200. Castermans D et al (2003) The neurobeachin gene is disrupted by a translocation in a patient with idiopathic autism. J Med Genet 40(5):352-6

201. Wang $X$ et al (2000) Neurobeachin: a protein kinase A-anchoring, beige/Chediak-higashi protein homolog implicated in neuronal membrane traffic. J Neurosci 20(23):8551-65

202. Medrihan L et al (2009) Neurobeachin, a protein implicated in membrane protein traffic and autism, is required for the formation and functioning of central synapses. J Physiol 587(Pt 21):5095-106
1799 
Mol Neurobiol

1865

1866

1867

1868

1869

1870

1871

1872

1873

1874

1875

1876

1877

1878

1879

1880

1881

1882

1883

1884

1885

1886

1887

1888

1889

1890

1891

1892

1893

1894

1895

1896

1897

1898

1899

1900

1901

1902

1903

1904

1905

1906

1907

1908

1909

1910

1911

1912

1913

1914

1915

1916

1917

1918

1919

1920

1921

1922

1923

1924

1925

1926

1927

1928

1929

1930
203. Volders K, Nuytens K, Creemers JW (2011) The autism candidate gene Neurobeachin encodes a scaffolding protein implicated in membrane trafficking and signaling. Curr Mol Med 11(3):204-17

204. de Souza N et al (2007) SEL-2, the C. elegans neurobeachin/ LRBA homolog, is a negative regulator of lin-12/Notch activity and affects endosomal traffic in polarized epithelial cells. Development 134(4):691-702

205. Shamloula HK et al (2002) rugose (rg), a Drosophila A kinase anchor protein, is required for retinal pattern formation and interacts genetically with multiple signaling pathways. Genetics 161(2):693-710

206. Katidou M et al (2008) The immunoglobulin superfamily of neuronal cell adhesion molecules: lessons from animal models and correlation with human disease. Biotechnol J 3(12):1564-80

207. Rosenthal A, Jouet M, Kenwrick S (1992) Aberrant splicing of neural cell adhesion molecule L1 mRNA in a family with Xlinked hydrocephalus. Nat Genet 2(2):107-12

208. Jouet $\mathrm{M}$ et al (1993) A missense mutation confirms the L1 defect in X-linked hydrocephalus (HSAS). Nat Genet 4(4):331

209. Fransen E et al (1995) CRASH syndrome: clinical spectrum of corpus callosum hypoplasia, retardation, adducted thumbs, spastic paraparesis and hydrocephalus due to mutations in one single gene, L1. Eur J Hum Genet 3(5):273-84

210. Marui $T$ et al (2009) Association of the neuronal cell adhesion molecule (NRCAM) gene variants with autism. Int J Neuropsychopharmacol 12(1):1-10

211. Zallen JA, Kirch SA, Bargmann CI (1999) Genes required for axon pathfinding and extension in the $C$. elegans nerve ring. Development 126(16):3679-92

212. Wang $X$ et al (2005) A role for the C. elegans L1CAM homologue lad-1/sax-7 in maintaining tissue attachment. Dev Biol 284(2):273-91

213. Sasakura $\mathrm{H}$ et al (2005) Maintenance of neuronal positions in organized ganglia by SAX-7, a Caenorhabditis elegans homologue of L1. EMBO J 24(7):1477-88

214. Pocock R et al (2008) Functional dissection of the C. elegans cell adhesion molecule SAX-7, a homologue of human L1. Mol Cell Neurosci 37(1):56-68

215. Wang X et al (2008) The C. elegans L1CAM homologue LAD-2 functions as a coreceptor in MAB-20/Sema2 mediated axon guidance. J Cell Biol 180(1):233-46

216. Castellani V et al (2000) Analysis of the L1-deficient mouse phenotype reveals cross-talk between Sema3A and L1 signaling pathways in axonal guidance. Neuron 27(2):237-49

217. Falk $J$ et al (2005) Dual functional activity of semaphorin $3 \mathrm{~B}$ is required for positioning the anterior commissure. Neuron 48(1):63-75

218. Wright AG et al (2007) Close homolog of L1 and neuropilin 1 mediate guidance of thalamocortical axons at the ventral telencephalon. J Neurosci 27(50):13667-79

219. Demyanenko GP, Shibata Y, Maness PF (2001) Altered distribution of dopaminergic neurons in the brain of L1 null mice. Brain Res Dev Brain Res 126(1):21-30

220. Demyanenko GP et al (2004) Close homolog of L1 modulates area-specific neuronal positioning and dendrite orientation in the cerebral cortex. Neuron 44(3):423-37

221. Demyanenko GP et al (2011) NrCAM deletion causes topographic mistargeting of thalamocortical axons to the visual cortex and disrupts visual acuity. J Neurosci 31(4):1545-58

222. Macosko EZ et al (2009) A hub-and-spoke circuit drives pheromone attraction and social behaviour in C. elegans. Nature 458(7242):1171-1175

223. Wu Q et al (2003) Developmental control of foraging and social behavior by the Drosophila neuropeptide Y-like system. Neuron 39(1):147-61
224. Karl T et al (2010) Schizophrenia-relevant behaviours in a genetic mouse model for Y2 deficiency. Behav Brain Res 207(2):434-40

225. Ramanathan S et al (2004) A case of autism with an interstitial deletion on $4 \mathrm{q}$ leading to hemizygosity for genes encoding for glutamine and glycine neurotransmitter receptor sub-units (AMPA 2, GLRA3, GLRB) and neuropeptide receptors NPY1R, NPY5R. BMC Med Genet 5:10

226. Kramer JM, van Bokhoven H (2009) Genetic and epigenetic defects in mental retardation. Int J Biochem Cell Biol 41(1):96-107

227. Bond $\mathrm{J}$ et al (2002) ASPM is a major determinant of cerebral cortical size. Nat Genet 32(2):316-320

228. Higgins $J$ et al (2010) Human ASPM participates in spindle organisation, spindle orientation and cytokinesis. BMC Cell Biol 11:85-85

229. van der Voet M et al (2009) NuMA-related LIN-5, ASPM-1, calmodulin and dynein promote meiotic spindle rotation independently of cortical LIN-5/GPR/Galpha. Nat Cell Biol 11(3):269277

230. Galli M et al (2011) aPKC phosphorylates NuMA-related LIN-5 to position the mitotic spindle during asymmetric division. Nat Cell Biol 13(9):1132-1138

231. Fraser AG et al (2000) Functional genomic analysis of $C$. elegans chromosome I by systematic RNA interference. Nature 408(6810):325-330

232. Simmer F et al (2003) Genome-wide RNAi of C. elegans using the hypersensitive rrf-3 strain reveals novel gene functions. PLoS Biol 1(1):E12-E12

233. Piano F et al (2002) Gene clustering based on RNAi phenotypes of ovary-enriched genes in C. elegans. Curr Biol 12(22):19591964

234. Pulvers JN et al (2010) Mutations in mouse Aspm (abnormal spindle-like microcephaly associated) cause not only microcephaly but also major defects in the germline. Proc Natl Acad Sci U S A 107(38):16595-16600

235. Laumonnier F et al (2005) Mutations in PHF8 are associated with $\mathrm{X}$ linked mental retardation and cleft lip/cleft palate. J Med Genet 42(10):780-786

236. Koivisto AM et al (2007) Screening of mutations in the PHF8 gene and identification of a novel mutation in a Finnish family with XLMR and cleft lip/cleft palate. Clin Genet 72(2):145-149

237. Qiu J et al (2010) The X-linked mental retardation gene PHF8 is a histone demethylase involved in neuronal differentiation. Cell Res 20(8):908-918

238. Kleine-Kohlbrecher D et al (2010) A functional link between the histone demethylase PHF8 and the transcription factor ZNF711 in X-linked mental retardation. Mol Cell 38(2-2):165-178

239. Stromme P et al (2002) Mutations in the human ortholog of Aristaless cause X-linked mental retardation and epilepsy. Nat Genet 30(4):441-5

240. Melkman T, Sengupta P (2005) Regulation of chemosensory and GABAergic motor neuron development by the $C$. elegans Aristaless/Arx homolog alr-1. Development 132(8):1935-49

241. Poirier K et al (2007) Large spectrum of lissencephaly and pachygyria phenotypes resulting from de novo missense mutations in tubulin alpha 1A (TUBA1A). Hum Mutat 28(11):105564

242. Baran R et al (2010) Motor neuron synapse and axon defects in a C. elegans alpha-tubulin mutant. PLoS One 5(3):e9655

243. Epstein CJ (2006) Down's syndrome: critical genes in a critical region. Nature 441(7093):582-583

244. Guipponi M et al (2000) C21 orf5, a novel human chromosome 21 gene, has a Caenorhabditis elegans ortholog (pad-1) required for embryonic patterning. Genomics 68(1):30-40

245. Rachidi $M$ et al (2007) New cerebellar phenotypes in YAC transgenic mouse in vivo library of human Down syndrome critical region-1. Biochem Biophys Res Commun 364(3):488-94
1931 
1997

1998

1999

2000

2001

2002

2003

2004

Q2 2005

2006

2007

2008

2009

2010

2011

2012

2013

2014

2015

2016

2017

2018

2019

2020

2021

2022

2023

2024

2025

2026

2027

2028

2029

2030

2031

2032

2033

2034

2035

2036

2037

2038

2039

2040

2041

2042

2043

2044

2045

2046

2047

2048

2049

2050

2051

2052

2053

2054

2055

2056

2057

2058

2059

2060

2061

2062
246. Rachidi M, Lopes C (2008) Mental retardation and associated neurological dysfunctions in Down syndrome: a consequence of dysregulation in critical chromosome 21 genes and associated molecular pathways. Eur J Paediatr Neurol EJPN Off J Eur Paediatr Neurol Soc 12(3):168-182

247. Arron JR et al (2006) NFAT dysregulation by increased dosage of DSCR1 and DYRK1A on chromosome 21. Nature 441(7093):595600

248. Dierssen M, de Lagrån MMN (2006) DYRK1A (dual-specificity tyrosine-phosphorylated and -regulated kinase 1A): a gene with dosage effect during development and neurogenesis. Sci World J 6:1911-1922

249. Park J, Song W-J, Chung K (2009) Function and regulation of Dyrk1A: towards understanding Down syndrome. Cell Mol Life Sci 66(20):3235-3240

250. Raich WB et al (2003) Characterization of Caenorhabditis elegans homologs of the Down syndrome candidate gene DYRK1A. Genetics 163(2):571-580

251. Altafaj, X., et al., Normalization of Dyrk1A expression by AAV2/ 1-shDyrk1A attenuates hippocampal-dependent defects in the Ts65Dn mouse model of Down syndrome. Neurobiol Dis, 2012

252. Guedj F et al (2009) Green tea polyphenols rescue of brain defects induced by overexpression of DYRK1A. PLoS One 4(2):e4606

253. Ortiz-Abalia J et al (2008) Targeting Dyrk1A with AAVshRNA attenuates motor alterations in TgDyrk1A, a mouse model of Down syndrome. Am J Hum Genet 83(4):479-88

254. Strippoli $\mathrm{P}$ et al (2000) A new gene family including DSCR1 (Down syndrome candidate region 1) and ZAKI-4: characterization from yeast to human and identification of DSCR1-like 2, a novel human member (DSCR1L2). Genomics 64(3):252-263

255. Fuentes JJ et al (2000) DSCR1, overexpressed in Down syndrome, is an inhibitor of calcineurin-mediated signaling pathways. Hum Mol Genet 9(11):1681-1690

256. Groth RD, Dunbar RL, Mermelstein PG (2003) Calcineurin regulation of neuronal plasticity. Biochem Biophys Res Commun 311(4):1159-1171

257. Nguyen T, Di Giovanni S (2008) NFAT signaling in neural development and axon growth. Int J Dev Neurosci Off J Int Soc Dev Neurosci 26(2):141-145

258. Lee JI et al (2003) The Caenorhabditis elegans homologue of Down syndrome critical region 1, RCN-1, inhibits multiple functions of the phosphatase calcineurin. J Mol Biol 328(1):147-156

259. Kalscheuer VM et al (2003) Mutations in the polyglutamine binding protein 1 gene cause $\mathrm{X}$-linked mental retardation. Nat Genet 35(4):313-315

260. Lenski $\mathrm{C}$ et al (2004) Novel truncating mutations in the polyglutamine tract binding protein 1 gene (PQBP1) cause Renpenning syndrome and X-linked mental retardation in another family with microcephaly. Am J Hum Genet 74(4):777-780

261. Lubs H et al (2006) Golabi-to-Hall syndrome results from a missense mutation in the WW domain of the PQBPI gene. J Med Genet 43(6):e30-e30

262. Takahashi, K., et al., Nematode homologue of PQBP1, a mental retardation causative gene, is involved in lipid metabolism. PLoS One, 2009. 4(1)

263. Gibbons RJ et al (1995) Mutations in a putative global transcriptional regulator cause X-linked mental retardation with alphathalassemia (ATR-X syndrome). Cell 80(6):837-845

264. Gibbons R (2006) Alpha thalassaemia-mental retardation, $X$ linked. Orphanet J Rare Dis 1:15-15

265. Picketts DJ et al (1996) ATRX encodes a novel member of the SNF2 family of proteins: mutations point to a common mechanism underlying the ATR-X syndrome. Hum Mol Genet 5(12):1899-1907

266. Kernohan KD et al (2010) ATRX partners with cohesin and $\mathrm{MeCP} 2$ and contributes to developmental silencing of imprinted genes in the brain. Dev Cell 18(2):191-202
267. Bender AM, Wells O, Fay DS (2004) lin-35/Rb and xnp-1/ATR$\mathrm{X}$ function redundantly to control somatic gonad development in C. elegans. Dev Biol 273(2):335-349

268. Cardoso $\mathrm{C}$ et al (2005) XNP-1/ATR-X acts with RB, HP1 and the NuRD complex during larval development in C. elegans. Dev Biol 278(1):49-59

269. Chubb JE et al (2008) The DISC locus in psychiatric illness. Mol Psychiatry 13(1):36-64

270. Soares DC et al (2011) DISC1: structure, function, and therapeutic potential for major mental illness. ACS Chem Neurosci 2(11):609-632

271. Chen S-Y, Huang P-H, Cheng H-J (2011) Disrupted-inschizophrenia 1-mediated axon guidance involves TRIO-RACPAK small GTPase pathway signaling. Proc Natl Acad Sci U S A 108(14):5861-5866

272. Briancon-Marjollet A et al (2008) Trio mediates netrin-1-induced Rac1 activation in axon outgrowth and guidance. Mol Cell Biol 28(7):2314-23

273. Kwok TC et al (2006) A small-molecule screen in C. elegans yields a new calcium channel antagonist. Nature 441(7089):91-5

274. Calamini B et al (2012) Small-molecule proteostasis regulators for protein conformational diseases. Nat Chem Biol 8(2):185-96

275. Wormbase. Available from: http://www.wormbase.org.

276. Rijkers K et al (2010) Polymorphisms in CACNA1E and Camk2d are associated with seizure susceptibility of SpragueDawley rats. Epilepsy Res 91(1):28-34

277. Genetics home reference. Available from: http://ghr.nlm.nih.gov/gene/

278. Liu Q, Hollopeter G, Jorgensen EM (2009) Graded synaptic transmission at the Caenorhabditis elegans neuromuscular junction. Proc Natl Acad Sci USA 106(26):10823-8

279. Thorgeirsson TE et al (2008) A variant associated with nicotine dependence, lung cancer and peripheral arterial disease. Nature 452(7187):638-42

280. Saitsu $\mathrm{H}$ et al (2008) De novo mutations in the gene encoding STXBP1 (MUNC18-1) cause early infantile epileptic encephalopathy. Nat Genet 40(6):782-8

281. Bellanger JM et al (2012) The doublecortin-related gene zyg- 8 is a microtubule organizer in Caenorhabditis elegans neurons. J Cell Sci 125(Pt 22):5417-27

282. Gonczy P et al (2001) zyg-8, a gene required for spindle positioning in $C$. elegans, encodes a doublecortin-related kinase that promotes microtubule assembly. Dev Cell 1(3):363-75

283. Ackman JB et al (2009) Abnormal network activity in a targeted genetic model of human double cortex. J Neurosci 29(2):313-27

284. Kerjan $G$ et al (2009) Mice lacking doublecortin and doublecortin-like kinase 2 display altered hippocampal neuronal maturation and spontaneous seizures. Proc Natl Acad Sci USA 106(16):6766-71

285. Alkuraya FS et al (2011) Human mutations in NDE1 cause extreme microcephaly with lissencephaly [corrected]. Am J Hum Genet 88(5):536-47

286. Willemsen MH et al (2012) Mutations in DYNC1H1 cause severe intellectual disability with neuronal migration defects. J Med Genet 49(3): 179-83

287. Fu AK et al (2005) Aberrant motor axon projection, acetylcholine receptor clustering, and neurotransmission in cyclin-dependent kinase 5 null mice. Proc Natl Acad Sci USA 102(42):15224-9

288. Chae $T$ et al (1997) Mice lacking p35, a neuronal specific activator of $\mathrm{Cdk} 5$, display cortical lamination defects, seizures, and adult lethality. Neuron 18(1):29-42

289. Topalidou I, van Oudenaarden A, Chalfie M (2011) Caenorhabditis elegans aristaless/Arx gene alr-1 restricts variable gene expression. Proc Natl Acad Sci U S A 108(10):4063-4068

290. Tucker $M$ et al (2005) The Caenorhabditis elegans aristaless orthologue, alr-1, is required for maintaining the functional and
2063 
Mol Neurobiol

structural integrity of the amphid sensory organs. Mol Biol Cell 16(10):4695-4704

291. Gloria-Soria A, Azevedo RBR (2008) npr-1 regulates foraging and dispersal strategies in Caenorhabditis elegans. Curr Biol 18(21):1694-1699

292. Rogers C et al (2003) Inhibition of Caenorhabditis elegans social feeding by FMRFamide-related peptide activation of NPR-1. Nat Neurosci 6(11):1178-1185

293. Asada $\mathrm{H}$ et al (1996) Mice lacking the $65 \mathrm{kDa}$ isoform of glutamic acid decarboxylase (GAD65) maintain normal levels of GAD67 and GABA in their brains but are susceptible to seizures. Biochem Biophys Res Commun 229(3):8915

294. Kulkarni SJ, Newby LM, Jackson FR (1994) Drosophila GABAergic systems. II. Mutational analysis of chromosomal segment $64 \mathrm{AB}$, a region containing the glutamic acid decarboxylase gene. Mol Gen Genet 243(5):555-64

295. Cossette $P$ et al (2002) Mutation of GABRA1 in an autosomal dominant form of juvenile myoclonic epilepsy. Nat Genet 31(2):184-9

296. DeLorey TM et al (1998) Mice lacking the beta3 subunit of the GABAA receptor have the epilepsy phenotype and many of the behavioral characteristics of Angelman syndrome. J Neurosci 18(20):8505-14

297. Schuler V et al (2001) Epilepsy, hyperalgesia, impaired memory, and loss of pre- and postsynaptic $\operatorname{GABA}(\mathrm{B})$ responses in mice lacking $\mathrm{GABA}(\mathrm{B}(1))$. Neuron 31(1):47-58

298. Lee D, Su H, O'Dowd DK (2003) GABA receptors containing Rdl subunits mediate fast inhibitory synaptic transmission in Drosophila neurons. J Neurosci 23(11):4625-34 


\section{AUTHOR QUERIES}

\section{AUTHOR PLEASE ANSWER ALL QUERIES.}

Q1. References 152 and 279 based on original manuscript we received were identical. Hence, the latter was deleted and reference list and citations were adjusted. Please check if appropriate.

Q2. Please check provided bibauthorname if correct. 